\title{
Comparative Efficacy of Three Bait Toxicants Against the Subterranean Termite Reticulitermes Santonensis (Isoptera/Blattoidea: Rhinotermitidae)
}

\author{
Khalid Z Rasib* and Denis J Wright \\ Department of Life Sciences, Pakistan \\ Received: 制: November 10, 2018; Published: ㄴㅔㅛ: November 27, 2018 \\ *Corresponding author: Khalid Z Rasib, Department of Life Sciences, Pakistan
}

\begin{abstract}
The study was aimed to provide data to assess the risk poses by termites being able to establish and multiply in the UK. This risk can be judged by determining the minimum number of individuals and biotic and abiotic conditions required for establishment of a termite colony. Workers of $R$. Santonensis were used to determine the minimum colony size that can be established in order to produce mini colonies under laboratory conditions. Survival was observed for initial termite number as low as ten under constant conditions at $25^{\circ} \mathrm{C}, 75 \%$ relative humidity over 28 weeks. Results showed that an initial termite number of 250 gave the greatest population survival. Increasing initial termite numbers caused a decrease in the survival in the laboratory. Survival decreased with time in the laboratory trials. Workers of Reticulitermes Santonensis were also baited with three commercially available insecticides to test their efficacy at different concentrations using treated bait matrix as Whatmann 1 filter paper to document the suppression and complete mortality.
\end{abstract}

Response of the subterranean termite R. Santonensis (Isoptera: Rhinotermitidae) to three bait toxicants, Imodacloprid, Thiamethoxam, and hexaflumuron, was evaluated. The results showed that during the 3-weeks test period, all termites were killed by Hexaflumuron at 1000ppm, Thiamethoxam at $100 \mathrm{ppm}$ and Imidacloprid at $300 \mathrm{ppm}$. As these insecticides are environmentally safe, adequately stable and non- repellent, so termites will take it up while feeding on the treated baits. Being 'slow-acting' (with postponed action), the effects of the termiticides are manifested only after termites have carried it back to the nest and distributed it among nest mates during mutual food exchange through stomodial and proctodial trophallaxis activities. The horizontal transfer of lethal effects of slow acting non-repellent termiticides can fulfil the requirements of a liquid bait model for their potential to termite control methods. The termite baiting system technologies are particularly appealing to those concerned with the potential risks associated with the large quantities of liquid termiticides necessary for the traditional chemical barrier treatments for termites' control. Choice and no-choice feeding bioassays using treated filter papers with bait toxicants (Thiamethoxam and Hexaflumuron) were also conducted to determine the consumption and mortality of Reticulitermes Santonensis termite in the laboratory. Control filter paper in no-choice and choice tests using distilled water as solvent was also evaluated. In choice bioassays, $R$. Santonensis workers preferred to feed on untreated filter paper rather than filter paper treated with Hexaflumuron and Thiamethoxam bait toxicants. In general, termite workers consumed more control paper than the treated paper. In case of Thiamethoxam bioassays, termite workers showed more feeding on control (322.0 $\mathrm{mg}$ ) than the Thiamethoxam treated paper $80.0,108,125.0,164.0,192.0 \mathrm{mg}$ at $100,10,2.5,1.0$ and $0.25 \mathrm{ppm}$. In the choice hexaflumuron bioassays, termite workers repeated the instinct and consequently consumed more of the untreated paper than the treated one.

The amount of paper consumed was 98.0, 120.0, 145.0, 177.0, $198.0 \mathrm{mg}$ at 1000, 500, 200, 50 and 10ppm respectively. Significantly smaller amounts of the treated filter papers were eaten in comparison with control baits when $R$. santonensis workers were exposed to hexaflumuron and thiamethoxam. The amount of the treated filter paper consumed was significantly different $(\mathrm{P}<0.0001)$ than the amount consumed in the case of untreated at all concentrations tested for the thiamethoxam. This decrease in treated filter paper consumption at higher doses in particular indicate the anti-feedant effects at higher doses in both cases. In general, a decrease in termite mortality was recorded in the choice test. In No Choice feeding bioassays, based on the results the percent mortality was greater and more apparent. Comparing the highest doses of each insecticide, Thiamethoxam proved more toxic with $100 \%$ mortality at $100 \mathrm{ppm}$, whereas hexaflumuron at $1000 \mathrm{ppm}$ provoked $90 \%$ mortality of the R. Santonensis workers. The use of bait toxicants like hexaflumuron, Thiamethoxam and Imidacloprid in termite baits is briefly discussed. These overall results indicate that Thiamethoxam is effective as a bait toxicant at $100 \mathrm{ppm}$; Imidacloprid at $300 \mathrm{ppm}$ and hexaflumuron at 3,000 ppm against R. Santonensis.

Keywords: Reticulitermes Santonensis; Termite; Imodacloprid; Thiamethoxam; Hexaflumuron

\section{Introduction}

Reticulitermes Santonensis has a localized distribution in south western France Clement et al. [1]. But causes serious damage in urban areas, especially in Paris due to its presence for a few decades. The presence of $R$ Santonensis in Paris was first reported in 1945 in 
a private garden in the $16^{\text {th }}$ arrondissement (ardt) and was officially noticed by C. Noirot in 1953 near the original sighting. This termite has currently infested more than half of the arrondissements in the city. Buildings are mainly infested but trees along streets have been observed to be attacked by termites since 1993. Between 1994 and 1995, treatment using baits considerably decreased the presence of termites attacking live trees in a Parisian street Lohou et al. [2]. However, a better understanding of how colonies and populations are organized is necessary to control these pests in a targeted and professional manner. Indeed, Reticulitermes spp. has a cryptic life and foraging habits that make their social structure difficult to determine. Moreover, $R$ Santonensis societies are known to be open, i.e., do not show inter-colonial aggression, so that they may form a vast underground network Clément et al. [3,4]. In urban areas control of termite still depends mainly on the use of highly persistent and environmentally problematic insecticides Pearce [5] so, effective alternatives are needed urgently. One of the possibilities for termite control is the use of bait technology. The ideal product for this purpose should be environmentally safe, adequately stable and non- repellent, so that termites will take it up while feeding. The product should also be 'slow-acting' (with post-poned action), so that the effects of the compound will be manifested only after termites have carried it back to the nest and distributed it among nest mates during mutual food exchange. Subterranean termites are one of the world's most economically important pests because they damage structural wood Hickin [6].

The pest control industry spends approximately two billion dollars a year to suppress termite infestations and/or try to avoid their damage to structures $\mathrm{Su}$ et al. [7]. Worldwide there are 15 species of subterranean termites that are considered to be economically important pests Hickin [6]. The most economically important species in Europe are the Reticulitermes spp. subterranean termites are very successful because of their eusociality. Social insects live in large family groups and work together for the good of the colony. The worker termite caste is the most numerous and is responsible for all of the labour in the colony. Worker termite tasks include taking care of the brood, maintaining and repairing the nest, and foraging for food Krishna [8]. Other castes, such as soldiers and functional reproductive, are entirely dependant on the worker termite for food (Grassé and Noirot, et al. [9]. Worker termites forage for food, bring it back to the colony, and feed all other nestmates. Therefore, worker termites are the caste that damages structural wood.

The number oftermites is known to havean effecton survivorship of individuals under experimental conditions Forschler et al. [10]. However, there is a paucity of information's available with regard to $R$. santonensis (Isoptera: Rhinotermitidae). Some authors have claimed that only 50 individuals of Reticulitermes species are required for colony establishment Jacquiot et al. [11,12]. While Hrdy believed that more than 50 individuals of $R$ lucifugus species were required to start a colony and that even with 250 individuals, survival was very low. Sen-sarma [13] reviewed laboratory tests on a number of Reticulitermes species 200-500 workers to be the optimum number. In contrast, Becker, et al. [14] mentioned having initiated colonies with less than ten larvae and workers. The arena and substrate used in Hardy's (1961) study were not mentioned although these factors may be of great importance for termite survival Lenz, et al. [15]. Haverty found that Reticulitermes species took longer than Coptotermes formosanus to reach caste ratio equilibrium, possibly because of the former's slow rate of differentiation. This may in turn mean that the rate of establishment under ideal conditions may be slower for Reticulitermes species relative to other termite genera. The number of individuals present in natural colonies has also been thought to dictate the number of individuals that should be used in laboratory colony Sen Sarma [13]. This may be an important fact to consider during experimental design to enable easier comparison between laboratory test and the field. In Reticulitermes species natural colonies are said to comprise thousands of individuals Nutting, et al. [16]. Termites (order: Isoptera) make up, together with mantids and cockroaches, the most primitive winged terrestrial insect taxon, the Dictyoptera Deitz [17]. The Isoptera are divided, dependent on the reference, in six or seven families Noirot, et al. [18-20], which can be further separated into evolutionary lower and higher termites. Higher termites are differentiated from lower termites mainly by the absence of symbiotic flagellates in their enlarged hindgut. The loss of these symbiotic microorganisms in the course of evolution is most likely due to the changed feeding habit of these species, most of which feed on soil or cultivate fungi in their mounds as symbiotic partner for the digestion of wood Noirot, et al. [18]. Phylogenetically lower termites, in contrast, depend on symbiotic protozoa in their intestinal tract for the degradation of lignocellulose Cleveland, et al. [21].

The novel concept of the pest management of subterranean termites utilizing termite baiting systems is a paradigm in the pest control field. The standard method of termite control for many years was to exclude termites from buildings with a liquid barrier treatment. The barrier is a "passive" treatment regime, following the initial application of termiticide. The utilization of termite baiting systems, with installation, monitoring, application of active ingredient, and continuous re-monitoring and re-application, as needed, constitutes an "active" treatment regime. Bait stations are designed to facilitate the consumption of a bait-toxicant and its transfer to the rest of the colony; the goal is termite population reduction or elimination $\mathrm{Su}$, et al. [22]. The discovery and use of termite baiting systems to treat subterranean termites created confusion and controversy in the industry (Potter 2004). Many questions arose concerning efficacy of this novel treatment, as well as questions concerning the variable time required before termites located the monitoring stations, fed on active ingredient, spread the material to others in the colony through the food exchange process of trophallaxis, achieved some sort of control of the termite population, and ultimately protected structures. Many factors would conceivably affect this time frame, including the species of subterranean termite, season of year, ambient temperature, colony size, moisture supply, palatability of the bait matrix used, number and distance between in-ground bait stations, and whether aboveground bait stations were utilized directly on active termite shelter tubes or in carton material in aerial nests. 
One of the major advantages of the baiting system approach is the capability of reducing populations of subterranean termites, with the possibility of suppressing or eliminating termite colonies Lax, et al. [23]. Some of the major disadvantages of the baiting system approach are the time and effort required in the "active" treatment regime; this approach has always been very labour-intensive and must be continuously monitored and maintained in order to perpetuate an area that is free of termites [22]. To date, all commercial baits are formulated to be slow acting. The first bait system was developed in 1990 by Dow Agro Sciences: the Sentricon ${ }^{\circledR}$ Termite Elimination System. The slow acting ingredient in this product is hexaflumuron [N-(3,5-dichloro-4-(1,1,2,2 tetrafluroethoxy) phenyl) amino) carbonyl)-2,6- diflurobenzamide]. Hexaflumuron, a benzophenylurea, is an insect growth regulator, which functions as a chitin synthesis inhibitor. Three commercial termite baiting systems are available in the market. The Sentricon $₫$ system Getty, et al. [24-27] utilizes hexaflumuron. The First Line® system and the Terminate ${ }^{\circledR}$ system both contain sulfluramid Ballard, et al. $[28,29]$. Claims are made that these three baiting systems are effective in reducing termite populations and protecting structures from termite infestations. The Sentricon ${ }^{\circledR}$ system makes the claim of "colony elimination."

One Strategy for the remedial control of subterranean termites is the use of slow acting non- repellent toxicant in a bait or as a dust .This strategy is based on the premise that an entire colony of subterranean termites can be destroyed even if only a small part of the existing gallery system is treated, because the toxicant is distributed to the entire colony by social interaction (trophallaxis and grooming) with the exposed foragers. Over the past decade the rationale of subterranean termite control with repellent chemical barriers has come under scrutiny, and an alternative paradigm of population suppression has emerged. This approach to termite control relies on non-repellent baits or insecticide treatments that do not stimulate behavioral defenses or avoidance. With the advent of these non-repellent treatments, an understanding of termite foraging and tunneling behavior in the subsurface soil environment has become increasingly important. For more than six decades, soil treatments with termiticides have been the conventional technique for controlling subterranean termites Su, et al. [22]. Even though baiting has become a popular termite control strategy in the past $10 y r s$, two thirds of the treatments by pest control companies are applications of liquid termiticides to soil Curl [30]. Research and development has focused on the slow acting insecticides in which mortality and the speed of kill are concentration dependent (Su et al. 1987). Slow-acting, nonrepellent termiticides are a relatively recent innovation in subterranean termite control. As with fastacting, nonrepellent termiticides such as chloropyrifos, they are designed to kill rather than merely repel termites Su et al. [31].

In recentyears, non-repellent termiticides have become popular alternatives for termite control industry. Approximately $60 \%$ of the termiticides used in 2002 were one of the non-repellent termiticides such as fipronil (Termidor, BASF Corp., Research Triangle Park, NC), imidacloprid (Premise, Bayer Environmental Service, Montvale, NJ) or chlorfenapyr (Phantom, BASF Corp.) Anonymous [32]. Because of their non repellency and apparent delayed action, it has been suggested that, unlike the repellent pyrethroid or fast-acting organic phosphate termiticides, these new termiticides may impact the subterranean termite populations Kard [33,34]. Subterranean termites (Isoptera: Rhinotermitidae) cause billions of dollars in structural damage annually around the world. Because of the economic significance of these termites, numerous monitoring and control tactics have been evaluated for their ability to detect and suppress termite activity Su, et al. [35-40]. Arguably, the two most widely used methods of subterranean termite control in the United States are soil applications of liquid termiticide and termite baiting systems [21]. Although liquid termiticide soil applications have been the predominant method of subterranean termite control for the past 50 years Thorne, et al. [10] termite bait systems have become an important competitor in the termite market over the past decade Potter, et al. [29]. Preventive and remedial treatments are commonly used to suppress or control subterranean termites in buildings.

The use of liquid termiticides as chemical barriers under and/or around buildings is thought to be an effective method for preventing termite entry into buildings. New non-repellent and slow-acting termiticides have recently appeared on the market and have rapidly gained popularity as soil-treatment agents. Even relatively small amounts of such newly commercialized chemicals can imbue soil with preventive and remedial properties. These chemicals include an oxadiazine compound (indoxacarb), neonicotinoids, phenyl pyrazole compound(s), (fipronil) and a pyrrole compound (chlorfenapyr). Their slow-acting efficacy and non-repellency towards subterranean termite species have been studied extensively Gahlhoff [41-44]. Previous experiments have demonstrated that termites gradually take more than a lethal dose of these chemicals because their non-repellency allows the active ingredients to be taken up while tunnelling, although termites can penetrate the treated soil to some extent. As a consequence, many termite foragers are affected and the whole colony finally suffers severe damage.

Soil treatments with liquids insecticides have been the major tool in subterranean termite control since the 1950s. In 2002, for example, soil termiticide applications accounted for $77 \%$ market share of the subterranean termite control business in the United States Anonymous [31]. The application of soil termiticides beneath a structure creates a barrier to exclude soil-borne termites. Because of the extensive foraging range of an underground colony, soil termiticide treatments usually do not impact the overall population of subterranean termites $\mathrm{Su}$, et al. [31]. The surviving colony continues to produce foragers and alates that further infest nearby areas. The termite control industry is reliance on soil termiticide barriers is one of the contributing factors for the continuing expansion of the Formosan subterranean termite, Coptotermes formosanus Shiraki, in the United States. Approximately $60 \%$ of the termiticides used in 2002 were one of the non-repellent termiticides such as fipronil (Termidor, BASF Corp., Research Triangle Park, NC), imidacloprid (Premise, Bayer Environmental Service, Montvale, NJ), or chlorfenapyr (Phantom, BASF Corp.) Anonymous [31]. 
Because of their non-repellency and apparent delayed action, it has been suggested that, unlike the repellent pyrethroid or fast-acting organic phosphate termiticides, these new termiticides may impact the subterranean termite populations [45-47].

Laboratory study indicated that termites exposed to sublethal doses of imidacloprid did not show aversion to the subsequent exposure and may continue to travel through the treated soil, resulting in the colony suppression Thorne, et al. [48]. Movement of exposed termites also may spread the nonrepellent toxicants to nestmates through trophallaxis and social grooming Ibrahim, et al. [49]. Shelton, et al. [39], however, reported that high concentration of fipronil (10 ppm) was needed for a successful transfer of lethal dose to recipients, but at such dose, the donors may be killed too fast for a substantial toxicant transfer to occur within the population. Imidacloprid is an insecticide exhibiting low mammalian toxicity. It acts on the insect nervous system by attaching to the acetylcholine binding sites, called nicotinergic receptors, on receiving nerve cells Abbink [50].

This mode of action prevents transmission of information at these binding sites, leading to a lasting impairment of the nervous system and eventually death of the insect Schroeder [51]. Mammals have few nicotinergic receptors; thus, imidacloprid has very low mammalian toxicity Sattelle et al. [52]. Subterranean termite baiting technology has been a major breakthrough in termite management and baiting systems have quickly captured a significant portion of the termite control market Pawson [53]; Su and Scheffrahn [22]; Potter et al. [54]. Soil treatments with a slowacting, non-repellent insecticide would result in elimination of termite populations in areas adjacent to the treatments Thorne and Breisch [43], Potter and Hillery [46]. Such a liquid-bait would be very desirable because it would provide population suppression by eliminating colonies one by one but have advantages over bait with the reduced labor of a soil termiticide. One proposed slow-acting, non-repellent termiticide is the new generation neonicotinoid imidacloprid Matsuda et al. [55]. Imidacloprid, a nicotine analog, is an insect-specific agonist of nicotinic acetylcholine receptors that has been reported to be nonrepellent to termites Matsuda et al. [54], Thorne and Breisch [42]. The concept of a baiting technique for termite pest management dates back to Esenther and Gray [56], with subsequent research investigating various slow-acting active ingredients Beard [57]; Esenther and Beal [58,59].

Baits using chitin synthesis inhibitors as an active ingredient are effective at controlling subterranean termites $\mathrm{Su}$ [59] $\mathrm{Su}$ and Scheffrahn [60], Rojas and Morales-Ramos [61]. Recent developments for control of subterranean termites include the use of monitoring-baiting programs Su [62]. Chitin synthesis inhibitors share a similar chemical structure as other benzoyl phenyl ureas. Their mode of action is by interfering with the polymerization pathway of chitin, inducing accumulation of the monomer uridine diphospho-Nacetylglucosamine and blocking its synthesis Beeman [63]. These benzoylphenyl ureas are slow-acting poisons (showing effects within weeks), allowing foraging termite workers to transfer the active ingredient among other members of the colony Su and Scheffrahn [64]. Reported effects of chitin synthesis inhibitors on subterranean termites mainly include defective molting of immature individuals Su and Scheffrahn $[65,66]$.

Baiting systems using active ingredients such as moult (chitin synthesis) inhibitors, have become widely used in the control of termites affecting housing. They are effective in eliminating colonies when used consistently over an extended period of time. However, their application against termite pests in agriculture and plantation or urban forestry has not yet been widely developed or specifically tailored for the purpose. They would almost certainly prove to be effective against subterranean pest species from among the lower termites, such as Reticulitermes and Coptotermes. Systems specifically designed for the treatment of termites on trees will probably become available in the future and will be a low-environmental-risk chemical method of control, because the chemicals can be targeted specifically at pest species of termites in baiting receptacles. Bait systems have already been tested and have shown promising results against R.Santonensis in Paris, where city officials are also co-operating with the Centre National de la Recherche Scientifique (CNRS) in a pilot study to investigate colony and population structure using molecular and chemical markers. Hopefully this knowledge will lead to a better understanding of the pest's invasion strategies and allow development of effective targeted control measures for Paris and other big cities (UNEP/ FAO/Global IPM Facility Expert Group on Termite Biology and Management 2000-02).

Although liquid applications are the primary method of termite control in the pest management industry, bait systems are widely used today, especially in situations where liquid treatments have failed Kistner and Sbragia [67]. Bait systems can be used effectively to control termite colonies in areas where they pose structural damage problems with limited accessibility Kistner, Sbragia [67]. Many studies have demonstrated that bait systems can eliminate entire colonies of subterranean termites Esenther and Gray [55]; Su [63]; Su et al. [68]; DeMark et al. [32]; Su et al. [69]; Grace et al. Su and Scheffrahn $[26,65,70-74]$, whereas liquid applications have been shown to not affect large portions of the termite population around a structure Su and Scheffrahn [75]. Colony elimination occurs because the slow acting nature of the ingested toxicant allows foragers time to return to the colony and transfer the toxic material to unexposed nestmates before killing the carrier Beard [57]; Sheets et al. [76]. Because bait systems work to eliminate colonies, they can provide long term protection to structures Chambers and Benson [69]; Grace and Su [77].

The first bait system, the Sentricon ${ }^{\circledR}$ Termite Elimination System, was developed in 1990 by Dow AgroSciences and was registered for use in 1994. Sentricon $\AA$ is a stand alone treatment that is not to be used in combination with liquid termiticides. Furthermore, Sentricon ${ }^{\circledR}$ is a monthly monitoring system and when termite infestations are found, the wood monitor is removed and the Recruit II $囚$ bait is inserted into the station. Now the most widely used bait system, the Recruit $\mathrm{II} \circledast$ bait utilizes a chitin synthesis inhibitor, hexaflumuron[N-(( (3,5-dichloro-4-(1,1,2,2tetrafluroethoxy)phenyl)-amino)carbonyl)-2,6 diflurobenzamide], as its active ingredient. Hexaflumuron has been used to control 
a variety of agricultural pests, but it is also useful against subterranean termites Su and Scheffrahn [66]; Su [63]; Chambers and Benson [68]; Su [69]. It is lethal at low concentrations and has no associated feeding deterrence Robertson and Su [69]. Sheets et al. [76] determined that the rate at which workers eliminate hexaflumuron from the body is slower than the rate they take up food. This delay causes a build-up of the toxicant to occur in the termite body. Since the introduction of the Sentricon ${ }^{\circledR}$ System, other bait systems have been designed and marketed. Another chitin synthesis inhibitor, diflubenzuron, is the active ingredient in the Exterra ${ }^{\circledR}$ Termite Interception and Bait System developed by Ensyntax. Like hexaflumuron, diflubenzuron, was firstintroduced as an insecticide for other insects, such as the gypsy moth and various caterpillar species. Due to its success in controlling these insects, diflubenzuron was evaluated for efficacy against subterranean termites Doppelreiter and Lorioth 1981). The Exterra ${ }^{\circledR}$ System is a monthly or quarterly monitoring system. The diflubenzuron bait, Requium ${ }^{\circledR}$ is inserted into the stations if termites are found feeding on the monitors.

The design of the Exterra ${ }^{\circledR}$ bait station allows for Requium ${ }^{\circledR}$ to be added to the station, without removing the wood monitors so foraging termites are not disturbed. The Exterra ${ }^{\circledR}$ System is also designed as a stand alone treatment. Although Exterra ${ }^{\circledR}$ seems to be structured similar to that of Sentricon $\AA$, diflubenzuron has not attained as high a level of success as hexaflumuron. Su and Scheffrahn [60] determined that C. formosanus were deterred from feeding on baits with diflubenzuron concentrations $>2 \mathrm{ppm}$ and had very low rates of consumption at concentrations of 500 and 1,000ppm diflubenzuron. Furthermore, mortality was lower for termites feeding on diflubenzuron treated wood than that for termites feeding on wood treated with hexaflumuron. A third widely used bait system was created by FMC in 1996, the Firstline ${ }^{\circledR}$ Termite Bait System. This system contains the slow acting stomach toxicant sulfluramid. Unlike the hexaflumuron diflubenzuron, sulfluramid works by disrupting energy metabolism in termites Valles and Koehler [78]. The First line ${ }^{\circledR}$ System consists of an in-ground station with up to four wooden monitors inside. The stations must be checked every three months for signs of infesting termites. If termites are found, the infested wooden monitors are replaced with a sulfluramid bait. Like diflubenzuron, sulfluramid deters feeding at higher concentrations and is usable only at a small range of concentrations (4-10ppm for $C$. formosanus and $18-30 \mathrm{ppm}$ for $R$. flavipes; Su and Scheffrahn [79]. Firstline ${ }^{\circledR}$ cannot be used as a stand alone treatment and must be used in combination with liquid applications.

Esenther and Gray [55] were the first to suggest using a slow acting toxicant for termite control. Many slow acting toxicants have been impregnated into wooden bait blocks and tested against subterranean termites, such as mirex Esenther and Beal [57], Paton and Miller [80] hydramethylnon Su et al. [81], avermectin B1 Su et al. [82], A-9248 (di iodomethyl para-toyl sulfone) Su and Scheffrahn [83] sulfluramid Su and Scheffrahn [79], hexaflumuron Su [62] and diflubenzuron Su and Scheffrahn [65]. Although many of these chemicals successfully reduced termite populations, special emphasis has been placed on the use of IGRs as the slow acting toxicant in bait systems. In addition to not killing foraging termites on contact and allowing sufficient time for the termites to return to the colony and feed unexposed nestmates, IGRs are also detrimental to the colony dynamics. Because IGRs induce presoldier and intercaste production in termites Lüscher [84]; Howard and Haverty et al. [85-88], the ratio of caste members inside a termite colony is disrupted and the production of foraging workers is reduced Hrdý and Křeček [89]; Haverty [90]. With more soldier termites, the colony has more dependent mouths to feed and fewer worker termites to find food. Therefore, IGRs, such as hexaflumuron, were the first toxicants to be marketed in bait systems. IGRs work by three different methods: as juvenile hormone analogues (JHA), as precocenes, and as chitin synthesis inhibitors Ware [91]. Juvenile hormones (JHs) are hormones in the insect's body direct normal growth, development, and maturation of insects. JHAs can mimic these hormones and disrupt insect development or their emergence as adults Ware [92]. Precocenes affect the corpus allatum, the gland that secrete hormones, primarily JH. These hormones are important insect hormones because they control reproduction, molting, and metamorphosis Ware [92]. Chitin synthesis inhibitors (CSIs) disrupt the insect molting process, which ultimately causes death in immature insects because they die in the process of shedding their exoskeleton.

It is the CSIs that are used as many termiticides, especially in the bait systems. CSIs are benzoylphenyl ureas (BPUs) insecticides and inhibit normal chitin formation in larvae Ishaaya [93] by causing abnormal deposits of endocuticle to accumulate Mulder and Gijswijt [94]. BPUs have also been shown to suppress fecundity and exhibit ovicidal toxicity in some species of insects due to the chitin component of their egg shells Ascher and Nemny [95], Sarasua and Santiago-Alvarez [96-98]. The use of CSIs in termite control is very favorable because they target only a few selective organisms and are not broad spectrum insecticides. The selectivity is due to many factors, including their toxicity only to immature arthropods and not vertebrates, to the fact that they must be ingested for activation, and to their slow activation Granett [99]; Horowitz et al. [100]. The selectivity of CSIs allows for safe use around mammals and nontarget organisms, for low rate of accumulation in the soil, and for low bio magnification in the environment Verloop and Ferrell [101]. Using CSIs in bait stations as a means to control subterranean termite infestations has become increasingly important (reviewed in Su and Scheffrahn [102].

Evidence indicates that CSIs provide an effective method for termite control because of their slow acting properties, their ability to increase presoldier production within the termite colony, their capacity to cause gut defaunation and subsequent starvation of termites, and their non-repellent nature Haverty and Howard [103]; Haverty et al. [104]; Howard; Howard and Haverty [85,105,106]; Jones [86]; Su et al. [87]; Su and Scheffrahn [88]. CSIs, such as hexaflumuron, were considered for use in bait systems because of their success in controlling agricultural pests. Hexaflumuron was found to be effective against many species of agricultural crop pests, such as army beetworm (Spodoptera 
exugua) Belda and Guerrero [107], the spiny bollworm (Earias insulana (Boisd) Horowitz et al. [100], the sugar beet weevil (Aubeonymusmariaefranciscae Roudier) Marco et al. PerezFarubism et al. [98], and a number of pests on apples and peaches Komblas et al. [108]. Furthermore, hexaflumuron has been observed to have some ovicidal activity Komblas and Hunter [109]; Horowitz et al. [110] and affect fecundity and egg hatchability in different insect species Asher et al. [111]; Horowitz et al. [110]; Marco and Vinuela [112]. Because hexaflumuron is useful against agricultural pests and the fact that it acts more quickly than other CSIs Sbragia et al. [113], Dow Agro Sciences began researching hexaflumuron for use in controlling subterranean termites. The use of baits for the control of subterranean termites has been a goal for decades Randall and Doody [114], with a significant amount of research effort during the past 30 yr Beard [56], Esenther and Beal [57,58]; French and Robinson [115]; French [116]; Su [59,62]; Grace et al. [117]; Forschler and Ryder [118,119]; Potter [29]; Haagsma and Bean [26]; Su and Scheffrahn [22]. The success of termite bait development rests not only in the knowledge of termite responses to the toxicant but also in an understanding of the biology and ecology of these insects Traniello and Thorne [120]; Lewis et al. [28]; Getty et al. [121,122]; Haverty et al. [24,121,122]. Many variables, such as seasonal weather patterns, predation, and competition between nearby colonies, size or age of a colony, and the number of alternative food sources available can affect the viability of a termite colony and confound the interpretation of the action of the bait Forschler and Ryder [118,119].

Because of the cryptic lifestyle of subterranean termites, it can be difficult to assess the efficacy of termite bait. From a research perspective, once bait is deployed it is imperative that there be a system for observing the effects on termites that does not include using the bait itself for monitoring. Because termites may return to a baited area, a distinction between termites of a previously baited colony and those from neighbouring colonies or species of Reticulitermes reinvading previously occupied sites must be made to determine whether suppression or elimination has been achieved Su and Scheffrahn [66]. Active subterranean termite monitoring stations that are known to be connected to a bait station or delivery device become important windows into a colony and a tool for observing the effects of baiting Su and Scheffrahn [66], Lewis et al. [28]. After a colony has been suppressed or eliminated as a result of baiting, identification of colonies invading the baited territory (monitoring stations previously occupied) is the final factor in understanding the success of this technology Getty et al. $[123,124]$. The slow mode of action of the slow acting toxicants can eliminate colonies of subterranean termites.The toxicant in this way is allowed to be distributed widely within colony, as has been demonstrated both in the laboratory and in the field.

The subterranean termite is truly a puzzle. It is the most destructive, xylophagous pest of human structures and economically important plants Potter [29,21]; Su and Scheffrahn [125]. Nationwide costs for prevention, control, and repair attributable to subterranean termites is estimated to be in excess of $\$ 1.7$ billion annually in 1993 Gold et al. [126]. A more recent analysis estimates these costs at $\$ 11$ billion annually Su [127]. Paradoxically, subterranean termites are also some of the most beneficial insects due to nutrient cycling of valuable biomass, particularly cellulose and lignin, which are resources that few other organisms are capable of degrading Kofoid [128], Thorne and Forschler [10]. Despite their economic impact, relatively little is known about these social insects. Weesner [129] comments that we have "only fragments of information" about these cryptic organisms yet adds that termite "control methods are initially based upon some knowledge of the biology of the particular species of termite involved." Indeed, the advent and widespread use of the chlorinated hydrocarbon termiticides as effective soil barriers following World War II vitiated widespread termite research efforts for much of the 20th century Ware [91]. Basic knowledge of the physiological and behavioural attributes of termites and the complex ecological relationships exhibited in their subterranean background is made difficult due to their cryptic mode of existence and was given minimal attention until the loss of Chlordane and related compounds to the United States and Australia in 1988 Kofoid 128, Weesner 129, Wilson [130].

This resulted in challenges in the termite control industry, with academic and industry scientists searching for alternative termiticides. Alternative termiticides formulated from organophosphate and pyrethroid chemistry were much morecostly and had limited residual efficacy and longevity in soil when compared to chlorinated hydrocarbons. The end of production and subsequent loss of availability of chlordane and related compounds to the rest of the world in 1998 resulted in an atmosphere of fear and doubt concerning the future of effective, economical termite control. Subterranean termites in the genus Reticulitermes, everpresent in North America, are well known for their destructive capability Pearce [5]. The principal component of their diet is wood, which is also the dominant structural element of the building construction industry Thorne and Forschler [10]. Their innate role as decomposers of wood and other vegetation in the natural ecosystem changes their status from beneficial insect to that of a "pest," depending on whether the subject of their attack is a fallen tree or the lumber in a home or other building. The continued growth and expansion of urbanization also creates conditions conducive to infestation by subterranean termites. Wood-framed structures, well-watered lawns, bark mulch adjacent to buildings, and firewood piles beckon to the termites to feast on the overabundance Pearce [5].

One beneficial effect that has arisen from these concerns is the increased emphasis on the research into the biology of subterranean termites, particularly as it relates to pest management Haverty et al. [121, 24]; Houseman, et al. [131-134]; Thorne and Forschler [10]. Alternative physical, mechanical, and chemical control methodologies have begun to be extensively researched Cornelius et al. [135]; Forschler and Henderson [136]; Gold et al. [37], Grace et al. [137]; Jones [86,138-141]. Biological control strategies for insects such as termites have been examined by Schmid-Hempel [142], Van Driesch and Bellows [143], Wright et al. [144]. For most of the twentieth century, control of subterranean termites relied 
on liquid barrier treatments with termiticides, placed under and around structures in order to protect them. With the advent of termite baiting systems during the end of the last century, there was a shift in termite treatments utilizing the baiting concept. Current termite management efforts, as well as efficacy studies, began to concentrate on baiting system technologies Traniello and Thorne [120], utilizing fenoxycarb Jones [138], Jones and Lenz [145], chitin synthesis inhibitors (hexaflumuron and diflubenzuron) or slow-acting stomach poisons (hydramethylnon, sulfluramid, and boric acid) as active ingredients Ballard [146]; Getty et al. [24]; Haagsma and Bean [26]; Lewis et al. [28]; Pawson and Gold [37]; Sheets et al. [76]; Su [79,62], Su and Scheffrahn [79], [65], [64, 66]; $\mathrm{Su}$ et al. [147]. The concept of a baiting technique for termite pest management dates back to Esenther and Gray [55], with subsequent research investigating various slow-acting active ingredients Beard [56]; Esenther and Beal $[57,58]$. The utilization of termite baiting system technologies was a natural outgrowth of the desire for pest management efficacy accomplished with reduced levels of pesticide use, as well as the emphasis on "reduced risk" strategies. The termite baiting system technologies were particularly appealing to those concerned with the potential risks associated with the large quantities of liquid termiticides necessary for traditional chemical barrier treatments for termite Control Pawson and Gold [52], as well as the need for another treatment option when a traditional termiticide treatment was not successful in protecting a structure.

The objective of a termite baiting system is the management of termite populations and is accomplished through distribution of a toxicant or inhibitor into a colony within a palatable food (cellulose) substrate Grace et al. [148], Thorne and Forschler [10]. The strategy relies on the foraging activity of the pseudergates (workers) to gather and introduce this material into the social fabric of a colony where it will be shared through trophallaxis and subsequently kills or inhibits the normal development and metamorphosis of colony members Potter [29]; Su [59, 62]; Su and Scheffrahn [64]. The goal of this management tactic is the eventual collapse and death of the colony, or to be "functionally" eliminated, as described by Su [62]. Regulatory perspectives and challenges for termite baiting system registration will be determined, ultimately, by bait-toxicant risk and efficacy results Sweeney [149]. It is important to note that time is required for foraging termites to locate the bait stations, consume sufficient active ingredient, and share with nest mates through trophallaxis in order to control termite populations. Each stage is dependent on the results of the previous stage, and when one event influences interdependence, rather than independence, is the result, particularly in a biologically complex system such as a subterranean termite colony Buchanan [150]. Several of the previously cited active ingredients of baiting systems have been investigated through laboratory and field bioassays to determine their efficacy against termite populations Forschler and Chiao [10], Rojas and Morales-Ramos [61], Su and Scheffrahn [59], Su et al. [147].

Several termite baiting systems utilizing these ingredients have entered the market place and are being marketed to pest control companies or directly to the public as a means to achieve the control of termites Ballard and Lewis [151]. While there is limited information available on the efficacy of termite baiting systems, unbiased scientific data comparing different systems under actual use situations, and in significant numbers, is generally lacking. This current report using termite Reticulitermes santonensis examined the evaluation of the efficacy of available termite baiting system and its bait-toxicant active ingredients. The following studies were conducted to evaluate several functional aspects of one such bait System, and its active ingredient, using hexaflumuron, Imidacloprid and Thiamethoxam bait toxicants. This report consists of three specific objectives:

\section{Objectives}

a. To determine the minimum Colony size that can be established in order to produce mini colonies suitable for population studies.

b. To conduct mortality bioassays with a range of fast (neuroactive) and slow acting (Insect Growth regulator) chemical termiticides.

c. To investigate the efficacy of termite Elimination System through feeding bioassays under choice and no-choice conditions with hexaflumuron and Thiamethoxam as bait-toxicants for subterranean termite R. santonensis.

\section{Material and Methods \\ Reticulitermes Santonensis}

$R$ Santonensis which causes an estimated several million euros worth of damage to street trees in the city of Paris alone, where there are about 90,000 trees worth around 2500 euros each. This species attacks deciduous trees indiscriminately, regardless of age and species. Among tree species attacked are the plane tree, chestnut tree, ash tree, wing nut (Pterocarya spp.), poplar, etc. The current distribution of $R$ Santonensis is north of the Gironde, Charentes, and Vendee; is prevalent in the Loire Valley, Normandy, Centre, Paris and its suburbs Guillaume [152]; and is random in other northern districts Bagneres [153]. In Paris, R. santonensis has become a significant pest to structures and trees Lohou et al. [2]. A colony of the subterranean termit, $R$ Santonensis was already based from France in 1960, and reared in the laboratory at Silwood Park campus under constant conditions $\left(25^{\circ} \mathrm{C}, 75 \% \mathrm{RH}\right)$. The colony was housed in a plastic container with compost and four tiers of Pine blocks. Within the container the termites had access to feed on the Pine blocks. To augment the mini colonies termites were taken from the stock culture and 200 termite workers with natural caste composition were gently tapped into a container and then gradually transferred to the main experimental culture box.

\section{Termite Augmentation and Number}

In order to establish the mini colonies of the termite $R$ Santonensis under laboratory conditions, Scot pine, which is one of the most susceptible wood species was used in this study. Wooden blocks (length $\times$ Width $\times$ thickness: $30 \times 4 \times 1 \mathrm{~cm}$ ) were cut and obtained from the commercial timber yard. They were cleaned and kept in a dry place before their use for one week. The test apparatus 
containing three types of the plastic boxes with specific dimensions ( Length $\times$ height $\times$ width: $395 \times 290 \times 255 \mathrm{~cm}, 395 \times 155 \times 255$ $\mathrm{cm}$ and $245 \times 160 \times 180 \mathrm{~cm}$ ) respectively. Appropriate amount of compost 1000 grams was added along with 200 termite workers in each large sized transparent box containing four tiers of pine blocks. Another set of 20 small sized plastic containers (Length $\times$ height $\times$ width: $245 \times 160 \times 180 \mathrm{~cm}$ ) were also used. In these boxes the number of termites released was, 10, 25, 50,100 and 250. Four replicates $(n=4)$ for each small boxes were used and randomised. Thus a total of 20 plastic containers were used to establish mini colonies. The termites were handled with a moist paint brush. Five Scot pine squares were added to each of the container. This experiment was run for 7 months. In this experiment workers or pseudergates of a uniform stage (approximately W5) were used, their morphology (Buchli, 1958) and their stomach contents were used to judge whether or not they were functional workers. All the containers were then covered with black polythene to minimise the effects of light and placed in the CT room at $26+1^{\circ} \mathrm{C}, \mathrm{RH} 75 \%$. Moisture in the containers was kept judiciously and checked twice in a month. After test period the survival was determined by the number of individuals present at the end of the experiment. The data were analysed statistically using $\mathrm{R}$ (2.6.0, R development core team, 2008) and Minitab release (Version, 15).

\section{Selection of the Termiticides}

Hexaflumuron, Thiamethioxam and Imidacloprid were selected. Different concentrations of the three toxicants were prepared using distilled water and acetone as solvents.

\section{Use of Hexaflumuron, Thiamethoxam and Imidacloprid bait toxicants}

To examine the efficacy of the hexaflumuron, imidacloprid and Thiamethoxam as bait toxicants, different concentrations/doses were prepared separately by diluting the termiticides formulation ( based on the solubility) in solvents (acetone or distilled water) to obtain desired concentrations of $0.3,1,3,10,100,300,1000$ and $3000 \mathrm{ppm}$. Four replicates for each concentration were used. Distilled water and acetone were used as control. Two pieces of Whatmann filter paper No. 1 (55mm in diam) were rolled and inserted inside the Wickes plumbing easy fit pipe $(15 \times 2 \mathrm{~mm}$ diam $)$ placing vertically in the $75 \mathrm{ml}$ Pyrex beaker containing respective termiticide concentrations to allow uniform absorption of the chemical by the filter papers adopting the principle of capillary action. Tubes along with treated filter papers were placed in a fume hood for one hour to facilitate evaporation of the chemical from filter papers. Then tubes were partially buried in compost horizontally in the petriplates with 20 termite workers and conditioned at $25^{\circ} \mathrm{C}, 75 \%$ relative humidity for 3 weeks. Termite's mortality and consumption was recorded after 3 weeks. The experimental arenas along with all units were dismantled after 3 weeks. In another set of long-term experiment which lasted over 12 weeks using a low as well as high concentration of Thiamethoxam or Hexaflumuron.

The concentrations tested were 0.1 and $2.5 \mathrm{ppm}$ for Thiamethoxam and 10, 200ppm for hexaflumuron .This long-term bioassay was conducted to observe the slow action and efficacy of the bait toxicants against workers of R. Santonensis. 200 termite workers were released in the large size transparent boxes contains the four tiers of the scot pine wood with sufficient compost. Four replicates for each concentration were used, thus a total of 20 units were used for this experiment. All the test units were conditioned at $25^{\circ} \mathrm{C}, 75 \%$ RH. Efficacy of thiamethoxam and hexaflumuron was determined at the end of experiment. Any survival in the respective boxes was recorded. Set up was dismantled after the 12 weeks.

\section{Feeding Bioassays}

Feeding bioassays were performed to determine mortality upon the ingestion of untreated and bait toxicant treated filter papers under choice and no-choice conditions.

\section{No Choice Termite Feeding Bioassay}

In this bioassay, two bait papers were selected and treated separately with different doses of two different bait toxicants (hexaflumuron and thiamethoxam) along with control, treated with distilled water. Baits were positioned in the centre of the petriplates.

\section{No Choice Bioassay Design}

Different doses of hexaflumuron (1000, 500, 200, 50,10ppm) and Thiamethoxam $(100,10,2.5,1,0.25 \mathrm{ppm})$ treated filter paper with bait toxicants were used separately. No choice bioassays were set up for each of the following combinations: Control with untreated roll filter papers; separate hexaflumuron and thiamethoxam treated filter papers at different concentrations for both bait toxicants. The test apparatus was maintained at 25 $\pm 1^{\circ} \mathrm{C}$ and $75 \%$ relative humidity. Following the feeding test, the $\%$ mortality and consumption was calculated. Four replicates were used per concentration of each termiticide. The data were analyzed statistically by the ANOVAs one way using R (2.6.0, R development core team, 2008) and Minitab release (Version, 15).

\section{Choice Termite Feeding Bioassay}

Bioassay arenas used in this choice feeding tests have two separate baits; one bait treated with hexaflumuron and other Thiamethoxam along with the control baits treated with distilled water. The baits were positioned side by side in separate petriplates.

\section{Choice Bioassay Design}

Separate choice bioassays for each bait toxicants dose were set up in the following combinations: 1000, 500, 200, 50 and 10ppm-hexaflumuron + control; $100,10,2.5,1$ and 0.25 ppmThiamethoxam + control. Termites placed inside choice arenas could simultaneously forage on two baits held in the same petri plate. Assembled Petri plates were kept at $25 \pm 1^{\circ} \mathrm{C}$ and $75 \% \mathrm{RH}$ for 21 days. After exposure, the percent mortality and consumption of the filter paper baits was recorded. Four replicates with 20 workers for each insecticide concentration/dose were tested.

\section{Statistical Analyses}

Data were analysed statistically using R (2.6.0, R development core team, 2008) and Minitab release (Version.15). 


\section{Results}

Minimum Number For Successful Termite Establishment Survival of Termites on Scot Pine Under Laboratory Conditions

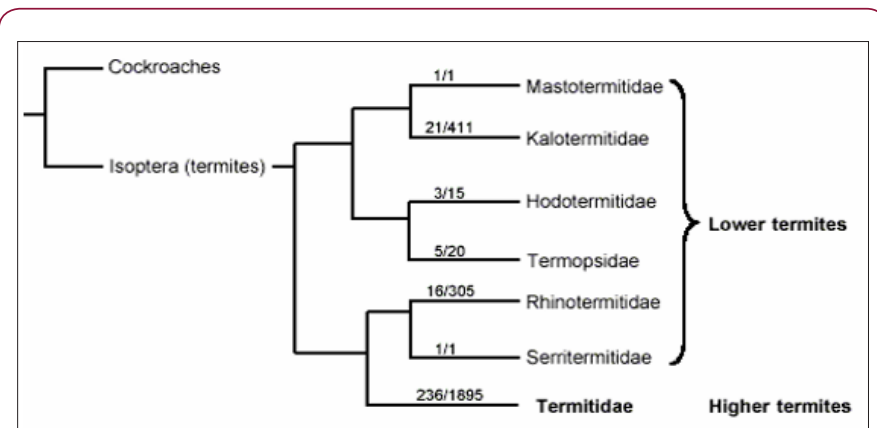

Figure 1: Showing a schematic outline of the phylogenetic relationships among the different termite families and the closely related cockroaches. The numbers on the lines represent the number of genera/species in the different families (After Abe. et al. 2000).

The results show that an initial termite number of 250 gave the greatest population survival. No nymph production was recorded in any initial termite number except at 250 with 38 numbers of nymphs. The standard error of the mean number surviving increased with increased initial termite number, and this is what would be expected as the variation is dependent on the number of termites present. A linear regression showed that initial termite number
(F1, 4= 9.51, p<0.05) had a significant effect on the survival (Figure 1). The proportion survival (0.96) was greatest at an initial termite number of 250 for $R$ Santonensis. The lowest proportion (0.25) was ten individuals. Final observations were taken 28 weeks after establishment of the experiment. Activity was seen in all containers that had received initial workers $10,25,50,100$ and 250.The results as presented in (Figure 2) show an increase in proportion survival with increased initial termite number. Interestingly, no nymph was observed in any container except at 250 initial termite numbers with 38 nymphs in all. The Regression analysis showed that initial termite number had a significant effect on termite survival after 28 weeks (F 1, 4= 9.51, p<0.05).

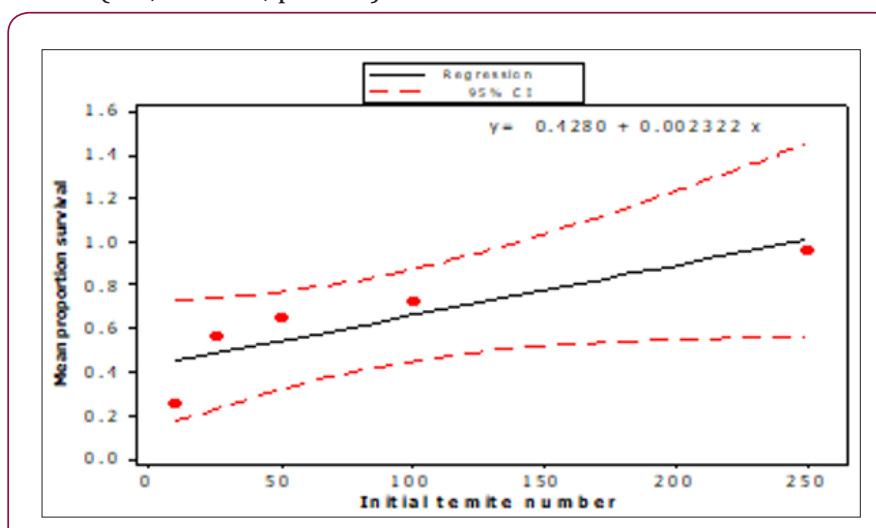

Figure 2: Proportion of R.Santonensis surviving after 28 weeks as a function of initial termite number $(n=4)$.

Table 1: Survival of $R$. Santonensis workers/ Pseudergates after 28 weeks as a function of initial termite number under laboratory conditions.

\begin{tabular}{|c|c|c|c|}
\hline Initial Termite Number & Mean Survival ( $\pm \mathbf{s e})$ & Mean Proportion Survival & No of Nymphs \\
\hline 10 & $2.5 .0 \pm 1.08$ & 0.25 & 0 \\
\hline 25 & $14.0 \pm 1.63$ & 0.56 & 0 \\
\hline 50 & $32.75 \pm 1.65$ & 0.65 & 0 \\
\hline 100 & $73.7 \pm 1.72$ & 0.73 & 38 \\
\hline
\end{tabular}

Note: Each value is the mean of 4 replicates; numbers within column followed by the same letter are not significantly different. (Tukeys' HSD, a=0.05).

\section{Comparative Efficacy Of Three Bait Toxicants}

Mean percent mortality for $R$ Santonensis workers exposed to different concentrations of three test termiticides is shown in Table 1 and Figure 1. At the lowest concentrations of thiamethoxam, hexaflumuron and imidacloprid $(0.3,10,0.3 \mathrm{ppm})$, the percent mortality recorded was $38.3,21.7$ and $35.0 \%$ respectively. At the highest concentrations of thiamethoxam, hexaflumuron and imidacloprid $(1000,3000,300 \mathrm{ppm})$, the mortality reached $100 \%$ after 3 weeks exposure. As concentrations of these three termiticides increased, the rate of mortality also increased eventually attaining $100 \%$ mortality. Comparing three termiticides at 10 and $100 \mathrm{ppm}$, the percent mortality for thiamethoxam, hexaflumuron and imidacloprid was 70, 21.7 and 60.2\%; 85, 36.7 and $86.6 \%$, indicating that hexaflumuron is slow in action than thiamethoxam and Imidacloprid. (Tables 2) indicate the lethal concentration (ppm) and toxicity of Imidacloprid, Thiamethoxam and Hexaflumuron against workers of R. santonensis after 3 weeks exposure as baits. Based on their LC50 values, Thiamethoxam proved more toxic than Imidacloprid followed by the hexaflumuron. The LC50 values are 2.41, 3.15 and 202.3 ppm for Thiamethoxam, Imidacloprid and hexaflumuron respectively (Table 2). Laboratory bioassays of termiticides offer valuable insight into understanding the activity of a chemical and in increasing the efficiency of applied termiticides. The means for all three termiticides were separated for each concentration using Tukey's Honest Significant Difference( HSD) test. Numbers within column followed by same letter indicate non significant differences at $(\alpha=0.05)$.The test was replicated four times for each concentration. (Table 1) Comparison of the Mean percent mortality $( \pm \mathrm{SE})$ of three baits toxicants against workers of $R$ Santonensis after 3 weeks laboratory trials. 
Table 2: Comparison of the Mean percent mortality $( \pm \mathrm{SE})$ of three baits toxicants against workers of $R$. santonensis after 3 weeks laboratory trials.

\begin{tabular}{|c|c|c|}
\hline Termiticides & Concentrations (ppm) & $\begin{array}{c}\text { Mean percent Mortality } \\
( \pm S E)\end{array}$ \\
\hline \multirow[t]{6}{*}{ Thiamethoxam } & 0.3 & $38.3 \pm 1.10 \mathrm{a}$ \\
\hline & 1 & $43.2 \pm 1.11 b$ \\
\hline & 3 & $48.3 \pm 1.15 c$ \\
\hline & 10 & $70.0 \pm 1.09 \mathrm{~d}$ \\
\hline & 100 & $85.0 \pm 1.15 \mathrm{e}$ \\
\hline & 1000 & $100 \pm 0.00 \mathrm{f}$ \\
\hline \multirow[t]{5}{*}{ Hexaflumuron } & 10 & $21.7 \pm 0.57 \mathrm{a}$ \\
\hline & 100 & $36.7 \pm 1.10 \mathrm{~b}$ \\
\hline & 300 & $55.0 \pm 1.15 c^{*}$ \\
\hline & 1000 & $63.3 \pm 1.3 c^{*}$ \\
\hline & 3000 & $100 \pm 0.00 \mathrm{~d}$ \\
\hline \multirow[t]{6}{*}{ Imidacloprid } & 0.3 & $35.0 \pm 1.10 \mathrm{a}$ \\
\hline & 1 & $45.0 \pm 1.11 b$ \\
\hline & 3 & $55.0 \pm 1.15 \mathrm{c}$ \\
\hline & 10 & $60.2 \pm 1.09 \mathrm{~d}$ \\
\hline & 100 & $86.6 \pm 1.14 \mathrm{e}$ \\
\hline & 300 & $100 \pm 0.00 \mathrm{f}$ \\
\hline Control & 0 & $1.7 \pm 0.11 \mathrm{~g}$ \\
\hline
\end{tabular}

Note: Each value is the mean of 4 replicates; numbers within column marked by asterisk $\left(^{*}\right)$ followed by the same letter for three different termiticides concentrations are not significantly different. (Tukeys' HSD, P<0.05).

Table 3: Lethal concentration (ppm) of Thiamethoxam and Imidacloprid and Hexaflumuron based baits against R. Santonensis after 3weeks exposure.

\begin{tabular}{|c|c|c|c|}
\hline Insecticide & Species & LC $_{\mathbf{1 0}}(\mathbf{9 5 \%} \mathbf{C I})$ & $\left.\mathbf{L C}_{\mathbf{5 0}} \mathbf{( 9 5 \%}_{\mathbf{C I}}\right)$ \\
\hline Thiamethoxam & & $0.06(0.01-0.23)$ & $2.41(1.31-4.44)$ \\
\hline Imidacloprid & R. Santonensis & $0.01(0.001-0.088)$ & $3.15(1.88-5.25)$ \\
\hline Hexaflumuron & & $8.70(3.47-21.7)$ & $202.3(136.2-300.5)$ \\
\hline
\end{tabular}

\section{Choice Feeding Bioassays}

The influence of doses on termite bait consumption varied considerably across the doses tested. Several of the low concentrations enhanced feeding; others deterred feeding depending on the concentration. At the highest concentrations 100 and $1000 \mathrm{ppm}$ of thiamethoxam and hexaflumuron presumably deterred feeding as determined by the low consumption of the filter paper baits ranged from $15-19 \%$ and had no significant effect at the two lower concentrations i.e., 0.25 and $10 \mathrm{ppm}$ where consumption ranged from $42-49 \%$ as compared to control with $81 \%$. Several of the concentrations elicited preferential feeding on paper baits in the choice bioassay. In general, termite workers fed preferentially more on control papers than the treated one. In thiamethoxam choice bioassays, termite workers showed more feeding on untreated bait papers ranged from $50-139 \mathrm{mg}$ at 100 to $0.25 \mathrm{ppm}$. While, the consumption of the treated paper baits for thiamethoxam ranged from $30-54 \mathrm{mg}$ at 100 to $0.25 \mathrm{ppm}$. Similarly, for hexaflumuron choice bioassays,

\section{No Choice Feeding Bioassay}

Interestingly, an increase in termite mortality was recorded with hexaflumuron and thiamethoxam treated filter paper at 1000 and 100 ppm when applied as bait toxicants than the control and the final mean mortality reached $90.0 \%-100 \%$ respectively (Table $3)$. This effect was more noticeable at higher treatment concentrations. A comparison of the effects of the two bait toxicants at 100 and $1000 \mathrm{ppm}$ demonstrated that termite mortality was significantly higher $(\mathrm{P}<0.05)$ for Thiamethoxam than hexaflumuron. In general, effect of all doses on mortality was significant $(\mathrm{F}=977.3 \mathrm{df}$ $=5,23, \mathrm{P}=0.05)$. The mean $\%$ mortality for hexaflumuron recorded was $90,78,57.5,30,23.7$ at 1000, 500, 200, 50 and 10ppm respectively.

In spite of the reduced consumption of filter paper bait as the dose of both toxicants increased, overall amount of treated filter paper bait ingested by termites still increased as the doses in both toxicants decreased (Table 3). Based on the results a significant percent mortality for hexaflumuron $(\mathrm{F}=184.8, \mathrm{df}=5,18, \mathrm{P}<0.05)$ and Thiamethoxam $(\mathrm{F}=172.08, \mathrm{df}=5,18, \mathrm{P}<0.05)$ was recorded under forced bioassays. Similarly, a significant mean percent consumption for hexaflumuron $(\mathrm{F}=599.8, \mathrm{df}=5,18, \mathrm{P}<0.05)$ and Thiamethoxam $(\mathrm{F}=276.4, \mathrm{df}=5,18, \mathrm{P}<0.05)$ was recorded. Comparing the effects of dose on mortality, Thiamethoxam proved more toxic with $100 \%$ mortality at $100 \mathrm{ppm}$, whereas hexaflumuron at 1000 ppm provoked $90 \%$ mortality. Filter paper baits $\%$ consumption for thiamethoxam ranged from $12-77.5 \%$ and for hexaflumuron, it was 17.7-77.5\% (Table 3). termite workers consumed more of the untreated bait papers than the treated one, consequently the consumption for untreated paper baits ranged from $60-100 \%$, while the treated filter paper weight loss was $30-53 \%$.The results clearly show the preferences of the termite workers to untreated rather than the treated bait papers. Difference in mass loss for each pair of paper baits both for thiamethoxam and hexaflumuron was significant $(\mathrm{P}=0.0001)$ using paired comparison t-test (Table 4). Overall, there was a significant difference in mortality values among termite workers exposed to different ppm hexaflumuron or thiamethoxam treated and control papers during the 3 weeks test period. The two pairs of untreated paper baits in a single control bioassay were evenly consumed. In contrast, probably feeding deterrence was observed in termite workers exposed to both hexaflumuron and thiamethoxam (Table 4). Significantly smaller amounts of the treated paper baits were eaten in comparison with untreated bait papers when termite workers were exposed to hexaflumuron or thiamethoxam. Interestingly, mortality was low under choice bioassays. The mean \% mor- 
tality for hexaflumuron ranged from $17.5-72.5$ at 1000 to $10 \mathrm{ppm}$. similarly, for thiamethoxam, it ranged from 25-84.Each untreated filter paper was paired with a treated $\mathrm{f}$ of each insecticide (treated/ untreated) separately in a Petri plate containing termites ( $n=4)$.Difference in mass loss for each pair of filter paper indicate significant difference (paired comparison t-test).

Table 4: $R$. Santonensis termite mortality and weight loss of hexaflumuron and thiamethoxam bait toxicants treated filter paper in 3 weeks no- choice laboratory bioassay.

\begin{tabular}{|c|c|c|c|c|c|}
\hline \multirow{2}{*}{ Concentration (ppm) } & \multirow{2}{*}{ Test } & \multirow{2}{*}{ Bioassay } & \multirow{2}{*}{ Mean \% mortality } & \multicolumn{2}{|c|}{ Filter paper weight loss } \\
\hline & & & & (mg) & $\%$ \\
\hline 0 & & Control & $5.0 \pm 0.00$ & $155.0 \pm 2.04 \mathrm{~A}$ & $77.5 \pm 1.63$ \\
\hline 100 & No-Choice & Thiamethoxam & $100 \pm 0.00$ & $24.0 \pm 0.82 \mathrm{~B}$ & $12.0 \pm 1.52$ \\
\hline 10 & & & $67.5 \pm 2.89$ & $36.0 \pm 0.80 \mathrm{C}$ & $18.0 \pm 1.23$ \\
\hline 2.5 & & & $46.2 \pm 2.50$ & $50.0 \pm 0.83 \mathrm{D}$ & $25.0 \pm 1.12$ \\
\hline 1.0 & & & $40.0 \pm 4.08$ & $65.0 \pm 0.77 \mathrm{E}$ & $32.5 \pm 1.15$ \\
\hline 0.25 & & & $34.0 \pm 4.79$ & $76.0 \pm 0.75 \mathrm{~F}$ & $38.0 \pm 1.17$ \\
\hline 1000 & No-Choice & Hexaflumuron & $90.0 \pm 5.37$ & $35.5 \pm 0.85 a$ & $17.7 \pm 1.42$ \\
\hline 500 & & & $76.2 \pm 4.78$ & $44.0 \pm 0.81 b$ & $22.0 \pm 1.36$ \\
\hline 200 & & & $57.5 \pm 2.88$ & $58.0 \pm 0.78 c$ & $29.0 \pm 1.25$ \\
\hline 50 & & & $30.0 \pm 4.08$ & $70.0 \pm 2.04 \mathrm{~d}$ & $35.0 \pm 1.18$ \\
\hline 10 & & & $23.7 \pm 2.50$ & $92.0 \pm 0.50 \mathrm{e}$ & $46.0 \pm 1.10$ \\
\hline
\end{tabular}

Note: Mean $( \pm S E)$ within a column followed by different letters are significantly different at the 0.05 level (Anova one way).

Mean percent mortality and consumption for hexaflumuron or thiamethoxam under choice and no choice conditions with their respective doses is represented in Figure 2. (Tables 5 \& 6) indicate the comparison of mean percent mortality and consumption under no choice and choice feeding bioassays. The means were separated by using Tukeys' HSD, $\mathrm{P}<0.05$ and anova one way results showed the significant effect of doses on mortality and consumption. (Tables $7 \& 8$ ) shows the comparison of the efficacy of thiamethoxam and hexaflumuron at their low vs. high concentrations. The impact of concentration and the duration on the mortality was highly significant $(\mathrm{F}=1065.2 ; \mathrm{df}=2,11 ; \mathrm{P}=0.000$ for thiamehoxam and for hexaflumuron it was $\mathrm{F}=354.6 ; \mathrm{df}=2,11 ; \mathrm{P}=0.000$ ) , therefore, termite mortality at $0.1-2.5$ for thiamethoxam ranged from 93.0-95.7\%, in contrast to the hexaflumuron, 10 and $200 \mathrm{ppm}$ concentrations provoked $76.7-92.1 \%$ mortality. The mean were separated statistically using Tukeys' HSD, at level 5.

Table 5: $R$ Santonensis and Mean weight loss of hexaflumuron and Thiamethoxam bait toxicants treated filter paper and control filter paper in a 3 weeks Choice laboratory bioassay.

\begin{tabular}{|c|c|c|c|c|c|}
\hline \multirow{2}{*}{ Concentration (ppm) } & \multirow{2}{*}{ Test } & \multirow{2}{*}{ Bioassay } & \multicolumn{2}{|c|}{ Mean Filter Paper Weight Loss (mg) } & \multirow{2}{*}{ T-test Probability } \\
\hline & & & Treated & Untreated & \\
\hline 0 & & Control & ------ & $322 \pm 2.40$ & ------ \\
\hline 1000 & Choice & Hexaflumuron+Control & $38 \pm 2.94$ & $60 \pm 3.08$ & $\mathrm{P}<0.0001$ \\
\hline 500 & & & $48 \pm 4.76$ & $80 \pm 3.16$ & $\mathrm{P}<0.0001$ \\
\hline 200 & & & $55 \pm 4.74$ & $87 \pm 2.02$ & $\mathrm{P}<0.0001$ \\
\hline 50 & & & $76 \pm 3.16$ & $101 \pm 4.69$ & $\mathrm{P}<0.0001$ \\
\hline 10 & & & $98 \pm 2.58$ & $100 \pm 0.81$ & $\mathrm{P}>0.05$ \\
\hline 100 & Choice & Thiamethoxam+control & $30 \pm 4.40$ & $50 \pm 2.83$ & $\mathrm{P}<0.0001$ \\
\hline 10 & & & $32 \pm 3.27$ & $76 \pm 3.65$ & $\mathrm{P}<0.0001$ \\
\hline 2.5 & & & $34 \pm 3.56$ & $91 \pm 2.58$ & $\mathrm{P}<0.0001$ \\
\hline 1.0 & & & $45 \pm 2.94$ & $119 \pm 3.63$ & $\mathrm{P}<0.0001$ \\
\hline 0.25 & & & $53 \pm 2.76$ & $139 \pm 3.37$ & $P<0.0001$ \\
\hline
\end{tabular}

Cite this article: Khalid Z Rasib, Denis J Wright. Comparative Efficacy of Three Bait Toxicants Against the Subterranean Termite Reticulitermes 
Table 6: Comparison of mean percent Mortality of $R$. Santonensis workers fed on Hexaflumuron and Thiamethoxam bait toxicants treated filter paper after 21 days under Choice and No choice bioassays.

\begin{tabular}{|c|c|c|c|c|c|}
\hline \multirow{2}{*}{ Concentration (ppm) } & \multirow{2}{*}{ Test } & \multirow{2}{*}{ Treatment Group } & \multirow{2}{*}{ Mean percent mortality $( \pm$ SE) } & \multicolumn{2}{|c|}{ F- Statistic } \\
\hline & & & & No choice & Choice \\
\hline 1000 & No Choice & Hexaflumuron & $90.0 \pm 0.82$ & \multirow{10}{*}{$\begin{array}{l}F=674.6 \\
d f=5,23 \\
P=0.000\end{array}$} & \multirow{10}{*}{$\begin{array}{l}F=291.5 \\
d f=5,23 \\
P=0.000\end{array}$} \\
\hline 1000 & Choice & Hexa + Control & $72.5 \pm 0.81$ & & \\
\hline 500 & No Choice & Hexaflumuron & $76.2 \pm 1.43$ & & \\
\hline 500 & Choice & Hexa + Control & $61.2 \pm 1.23$ & & \\
\hline 200 & No Choice & Hexaflumuron & $57.5 \pm 0.79$ & & \\
\hline 200 & Choice & Hexa + Control & $46.2 \pm 2.02$ & & \\
\hline 50 & No Choice & Hexaflumuron & $30.0 \pm 2.04$ & & \\
\hline 50 & Choice & Hexa + Control & $26.2 \pm 2.44$ & & \\
\hline 10 & No Choice & Hexaflumuron & $23.7 \pm 1.23$ & & \\
\hline 10 & Choice & Hexa + Control & $17.5 \pm 1.43$ & & \\
\hline 100 & No Choice & Thiamethoxam & $100 \pm 0.00$ & \multirow{12}{*}{$\begin{array}{l}F=397.2 \\
d f=5,23 \\
P=0.000\end{array}$} & \multirow{12}{*}{$\begin{array}{l}F=429.2 \\
d f=5,23 \\
P=0.000\end{array}$} \\
\hline 100 & Choice & Thia + Control & $84.0 \pm 0.81$ & & \\
\hline 10 & No Choice & Thiamethoxam & $67.5 \pm 2.14$ & & \\
\hline 10 & Choice & Thia + Control & $55.0 \pm 2.04$ & & \\
\hline 2.5 & No Choice & Thiamethoxam & $46.2 \pm 0.82$ & & \\
\hline 2.5 & Choice & Thia + Control & $40.0 \pm 0.79$ & & \\
\hline 1.0 & No Choice & Thiamethoxam & $39.0 \pm 1.84$ & & \\
\hline 1.0 & Choice & Thia + Control & $32.5 \pm 0.80$ & & \\
\hline 0.25 & No Choice & Thiamethoxam & $34.0 \pm 1.63$ & & \\
\hline 0.25 & Choice & Thia + Control & $25.0 \pm 2.03$ & & \\
\hline 0 & No Choice & 1 untreated paper & $5.0 \pm 0.80$ & & \\
\hline 0 & Choice & 2 untreated & $3.75 \pm 0.41$ & & \\
\hline
\end{tabular}

Note: Means percentage of mortality for each bait toxicant concentration are significantly different $(\mathrm{P}=0.000)$ by ANOVAs one way).

Table 7: Comparison of mean percent consumption of R. santonensis workers fed on Hexaflumuron; Thiamethoxam bait toxicants treated filter paper after 21 days under Choice and No choice bioassays.

\begin{tabular}{|c|c|c|c|c|c|}
\hline \multirow{2}{*}{ Concentration (ppm) } & \multirow{2}{*}{ Test } & \multirow{2}{*}{ Treatment Group } & \multirow{2}{*}{$\begin{array}{c}\text { Mean percent } \\
\text { mortality }( \pm \text { SE) }\end{array}$} & \multicolumn{2}{|c|}{ F- Statistic } \\
\hline & & & & No choice & Choice \\
\hline 1000 & No Choice & Hexaflumuron & $17.7 \pm 0.83$ & \multirow{10}{*}{$\begin{array}{l}F=82.2 \\
d f=5,23 \\
P=0.000\end{array}$} & \multirow{10}{*}{$\begin{array}{l}F=193.8 \\
d f=5,23 \\
P=0.000\end{array}$} \\
\hline 1000 & Choice & Hexa + Control & $24.5 \pm 0.81$ & & \\
\hline 500 & No Choice & Hexaflumuron & $22.0 \pm 0.78$ & & \\
\hline 500 & Choice & Hexa + Control & $32.0 \pm 0.81$ & & \\
\hline 200 & No Choice & Hexaflumuron & $29.0 \pm 1.63$ & & \\
\hline 200 & Choice & Hexa + Control & $35.5 \pm 2.04$ & & \\
\hline 50 & No Choice & Hexaflumuron & $35.0 \pm 0.81$ & & \\
\hline 50 & Choice & Hexa + Control & $44.2 \pm 1.63$ & & \\
\hline 10 & No Choice & Hexaflumuron & $46.0 \pm 2.44$ & & \\
\hline 10 & Choice & Hexa + Control & $49.5 \pm 1.84$ & & \\
\hline 100 & No Choice & Thiamethoxam & $12.0 \pm 1.52$ & \multirow{5}{*}{$\begin{array}{l}F=333.4 \\
d f=5,23 \\
P=0.000\end{array}$} & \multirow{5}{*}{$\begin{array}{l}F=357.1 \\
d f=5,23 \\
P=0.000\end{array}$} \\
\hline 100 & Choice & Thia + Control & $20.0 \pm 1.54$ & & \\
\hline 10 & No Choice & Thiamethoxam & $18.0 \pm 1.23$ & & \\
\hline 10 & Choice & Thia + Control & $27.0 \pm 2.25$ & & \\
\hline 2.5 & No Choice & Thiamethoxam & $25.0 \pm 1.12$ & & \\
\hline
\end{tabular}

Cite this article: Khalid Z Rasib, Denis J Wright. Comparative Efficacy of Three Bait Toxicants Against the Subterranean Termite Reticulitermes Santonensis (Isoptera/Blattoidea: Rhinotermitidae). Biomed J Sci \& Tech Res 11(3)-2018. BJSTR. MS.ID.002107. 


\begin{tabular}{|c|c|c|c|}
\hline 2.5 & Choice & Thia + Control & $31.2 \pm 1.43$ \\
\hline 1.0 & No Choice & Thiamethoxam & $32.5 \pm 1.15$ \\
\hline 1.0 & Choice & Thia + Control & $41.0 \pm 3.89$ \\
\hline 0.25 & No Choice & Thiamethoxam & $38.0 \pm 1.17$ \\
\hline 0.25 & Choice & Thia + Control & $48.0 \pm 2.44$ \\
\hline 0 & No Choice & 1 untreated paper & $72.5 \pm 1.63$ \\
\hline 0 & Choice & 2 untreated & $80.5 \pm 1.46$ \\
\hline
\end{tabular}

Table 8: Comparison of the efficacy of Thiamethioxam and Hexaflumuron at low vs. high concentrations for 12 weeks in the laboratory conditions.

\begin{tabular}{|c|c|c|c|c|}
\hline \multirow{2}{*}{ Concentration (ppm) } & \multicolumn{2}{|c|}{ Mean $( \pm$ SE) Mortality } & \multirow{2}{*}{ Mean \% Mortality } & \multirow{2}{*}{ F-statistic } \\
\hline & Thiamethoxam & Hexaflumuron & & \\
\hline 0.1 & $186.0 \pm 1.58 \mathrm{a}$ & & 93.0 & $\mathrm{~F}=1065.2$ \\
\hline 2.5 & $191.5 \pm 0.64 b$ & & 95.7 & $\begin{array}{c}\mathrm{df}=2,11 \\
\mathrm{P}=0.000\end{array}$ \\
\hline 10 & & $153.5 \pm 2.27 \mathrm{c}$ & 76.7 & $F=354.6$ \\
\hline 200 & & $184.2 \pm 3.85 \mathrm{~d}$ & 92.1 & $\mathrm{df}=2,11$ \\
\hline 0 & \multicolumn{2}{|c|}{$5.75 \pm 0.47 \mathrm{e}$} & 2.87 & $\mathrm{P}=0.000$ \\
\hline
\end{tabular}

Note: Each value is the mean of 4 replicates; numbers within column followed by different letter are significantly different. (Tukeys' HSD, P<0.05).

\section{Discussion}

Termites being terrestrial and social insects inhibiting nearly two-thirds of the Earth's land surface between $45^{\circ} \mathrm{N}$ and $\mathrm{S}$ latitude Wood and Sands [154], but are also present in temperate zones (e.g., Marini and Mantovani [155]. Their numbers can exceed 6000 individuals per $\mathrm{m}^{2}$, and their biomass often surpasses that of mammalian herbivores Lee and Wood [156]; Collins [157], which already indicates their enormous ecological impact. More than 2,600 termite species are found throughout the world, particularly in the tropical and subtropical regions Kambhampati and Eggleton [158]. Among these, 183 species are known to damage buildings, and 83 species cause significant damage to buildings. Subterranean termites account for $80 \%$ (147 species) of the economically important species worldwide. Reticulitermes is the only known indigenous subterranean termite species present in Europe. Its range has been expanding rapidly in the twentieth century notably along lines of transportation such as railways and canals, particularly in France Fougerousse \& Perlade [159]. In France, the genus Reticulitermes is composed of approximately six species/ subspecies Clement et al. [1]. One of these species, Reticulitermes santonensis Feytaud, occurs in sympatric zones in southwestern France with Reticulitermes grassei Clement. The current distribution of $R$ santonensis is north of the Gironde, Charentes, and Vendee; is prevalent in the Loire Valley, Normandy, Centre, Paris and its suburbs (Guillaume [152]; and is random in other northern districts Bagneres [153]. In Paris, R. Santonensis has become a signficant pest to structures and trees Lohou et al. [2], more so than when previously discussed by Jacquiot [11]. Feytaud [160] first described Charente, France, populations of Reticulitermes lucifugus as a subspecies, R. lucifugus santonensis. Feytaud [161] and Jucci [40] compared this subspecies to the American species
R. flavipes and concluded that they were similar, if not the same species. Feytaud [161] later supported the hypothesis of its synonymy with the North American Reticulitermes flavipe (Kollar), suggesting an introduction through La Rochelle harbor. Subsequent investigations by Feytaud [162], Lash [163], and Grasse' [164] collectively defined R. santonensis as a different species with a small geographic localization (in southwestern France).

The UK infestation that appear to have resulted from accidental importation of Reticulitermes spp. from their indigenous areas of distribution. Other cases of accidental importation have been reported in Hamburg (Germany), Hallein and Salzburg (Austria) (Reticulitermes flavipes) Fougerousse \& Perlade [159], Montreal (R. flavipes) (Canada) (Myles 1996), Montevideo (Uruguay) (R. lucifugus) Aber \& Fontes [165] and Santiago (Reticulitermes Hesperus) (Chile) Cabrera \& Camusseicht [166]. Europe has the least termite diversity among the world's populated continents. Less than 10 species occur in natural habitats and the most important genus is Reticulitermes. This genus currently contains five species that are widespread along the Mediterranean coastline of Spain, France, Italy, Balkans, and Greece. Although native species of Reticulitermes exist in Europe, there are still questions about their origins and relatedness with species from eastern North America. In parts of Europe Reticultermes kills living trees, an unusual occurrence in North America. Research Continues in Europe using insect chemistry, molecular genetics, and behaviour in mapping out species distribution and describing inter-colony interactions (UNEP/FAO/Global IPM Facility Expert Group on Termite Biology and Management 2002).

Subterranean termites of the genus Reticulitermes are important components of natural woodland ecosystems in temperate zones. Reticulitermes santonensis Feytaud has a "natural" distribution 
very localized in south-western France Clement et al. [1]. But this species also causes serious damage in urban areas, especially in Paris where it has been present for a few decades. Its presence in Paris was first reported in 1945 in a private garden in the 16th arrondissement (ardt). But it was officially noticed by Noirot in 1953 near the original sighting. This termite has spread and currently infests more than half of the arrondissements in the city. Buildings are mainly infested but trees along streets have been observed to be attacked by termites since 1993. Between 1994 and 1995, treatment using baits considerably decreased the presence of termites attacking live trees in a Parisian street Lohou et al. [2]. Indeed, Reticulitermes spp. has a cryptic life and foraging habits that make their social structure difficult to determine. Moreover, R. santonensis societies are known to be open, i.e., do not show intercolonial aggression, so that they may form a vast underground network Clement [3]; Clement and Lange [4]; Clement et al. [167]. However, a better understanding of how colonies and populations are organized is necessary to control these pests in a targeted and efficient manner. Survival and a minimum number of termite's worker for establishing a successful mini colony. Our current work on R. santonensis provides data to assess the risk poses by termites being able to establish and multiply. This risk can be judged by determining the minimum number of individuals and biotic and abiotic conditions required for establishment of a termite colony. Workers of R. santonensis were used to determine the minimum colony size that can be established in order to produce mini colonies under laboratory conditions. Survival was observed for initial termite number as low as ten under constant conditions at $25^{\circ} \mathrm{C}$, $75 \%$ relative humidity over 28 weeks. Results showed that an initial termite number of 250 gave the greatest population survival with 38 nymphs and interestingly, no nymph production was recorded in any of the test container except at 250 initial termite numbers. This suggests that a minimum number of termite's worker required establishing a successful mini colony is 250 .

Our results are in agreement with the findings of Sen-sarma [13] who reviewed laboratory tests on a number of Reticulitermes species and suggesting that 200-500 workers to be the optimum number to establish a successful mini termite colony. The number of termites is known to have an effect on survivorship of individuals under experimental conditions Forschler [118]. However, there is a paucity of information's available with regard to R. santonensis (Isoptera: Rhinotermitidae). Some authors have claimed that only 50 individuals of Reticulitermes species are required for colony establishment Jacquiot [11]; Serment \& Tourteaux [12]. While Hrdy [168] believed that more than 50 individuals of $R$. lucifugus species were required to start a colony and that even with 250 individuals, survival was very low. Sen-sarma [13] reviewed laboratory tests on a number of Reticulitermes species 200-500 workers to be the optimum number. In contrast, Becker [14] mentioned having initiated colonies with less than ten larvae and workers. The arena and substrate used in Hardy's [168] study were not mentioned although these factors may be of great importance for termite survival Lenz \& Williams [15].
Haverty [85] found that Reticulitermes species took longer than Coptotermes formosanus to reach caste ratio equilibrium, possibly because of the former's slow rate of differentiation. This may in turn mean that the rate of establishment under ideal conditions may be slower for Reticulitermes species relative to other termite genera. The number of individuals present in natural colonies has also been thought to dictate the number of individuals that should be used in laboratory colony Sen-sarma [13]. This may be an important fact to consider during experimental design to enable easier comparison between laboratory test and the field. In Reticulitermes species natural colonies are said to comprise thousands of individuals Nutting [16]. The genus Reticulitermes seems to have been in existence since the Oligocene epoch (24 to 37 millions years ago) (Grasse, 1949; Plateaux \& Clement, [4]). Species from this genus are often called 'subterranean' termites with their association with the soil, although this association is not obligatory Weesner, [129]; Forschler [[10]. They are used to consider being part of the lower termites but are now thought to be an intermediate between the higher and lower termites and are therefore, also termed 'middle' termites (Snyder, 1920; Harris \& Sands, 1965; Weesner [129]; Noirot \& Pasteels, 1987; Takesmatsu, 1992). Reticulitermes is the only known indigenous subterranean termite species present in Europe. Its range has been expanding rapidly in the twentieth century notably along lines of transportation such as railways and canals, particularly in France Fougerousse \& Perlade [159]. Reticulitermes species are from temperate regions and their colonies undergo seasonal changes Grasse [164]. This seasonality may be witnessed by a change in feeding habits, activity and movement deeper into the soil during colder periods Grasse [164]; Forschler [10]. The genus occurs in Palaearctic and Nearctic regions, but has also, in recent decades been accidently introduced into South America Weesner [129]; Aber and Fontes [165]; Myles, personal communication). In France, the genus Reticulitermes is composed of approximately six species/subspecies Clement et al. [1]. Europe has the least termite diversity among the world's populated continents. Less than 10 species occur in natural habitats and the most important genus is Reticulitermes.

This genus currently contains five species that are widespread along the Mediterranean coastline of Spain, France, Italy, Balkans, and Greece. Although native species of Reticulitermes exist in Europe, there are still questions about their origins and relatedness with species from eastern North America. In parts of Europe Reticultermes kills living trees, an unusual occurrence in North America. Research Continues in Europe using insect chemistry, molecular genetics and behaviour in mapping out species distribution and describing inter-colony interactions (UNEP/FAO/Global IPM Facility Expert Group on Termite Biology and Management 2002). The UK infestation that appear to have resulted from accidental importation of Reticulitermes spp. from their indigenous areas of distribution. Other cases of accidental importation have been reported in Hamburg (Germany), Hallein and Salzburg (Austria) (Reticulitermes flavipes) Fougerousse \& Perlade [159], Montreal (R. flavipes) (Canada) (Myles 1996), 
Montevideo (Uruguay) (R. lucifugus) Aber \& Fontes [165] and Santiago (Reticulitermes hesperus) (Chile) Cabrera \& Camusseicht [166].

$R$ Santonensis found in France and some urban areas of Europe is synonymous with North American Reticulitermes flavipes (Bagneres et al., 1990; Clement et al., [1]; Jenkins et al., 2001; Marini and Mantovani, [155]; Vieau, 2001; Dronnet etal., unpublished data). $R$ Santonensis, which causes an estimated several million euro's worth of damage to street trees in the city of Paris alone, where there are about 90,000 trees worth around 2500 euro's each. This species attacks deciduous trees indiscriminately, regardless of age and species. Among tree species attacked are the plane tree, chestnut tree, ash tree, wing nut (Pterocarya spp.), poplar, etc. Therefore, has become a significant pest to structures and trees Lohou et al. [2]. The current distribution of $R$ Santonensis is north of the Gironde, Charente's, and Vendee; is prevalent in the Loire Valley, Normandy, Centre, Paris and its suburbs Guillaume [152]; and is random in other northern districts Bagneres [153]. The aim of this study was to assess the minimum number of individuals for survival of a group of $R$ santonensis workers/ pseudergates under favourable conditions in the UK. This is particularly more important when posing the question of how many termites would need to be introduced accidentally for a viable colony to form. The specific objectives of the experiment were to determine the relative importance of termite number, estimate the number of termites required for establishment and finally to attempt to draw comparisons between laboratory experiments. The results from the experiment showed a downward trend in survival from 10 to 250 termites per container for $R$ Santonensis. In our experiment on R. santonensis, although the number of the surviving adult workers was slightly decreased, but interestingly, a total of 38 nymphs were produced at 250 initial termite numbers. This finding signifies that 250 initial termite numbers is sufficient to establish a successful colony. However, (Laetitia \& Wright, 2002) experiment with lower termite number (5-25) there was a positive trend. Grasse \& Chauvin [169] also found that survival increased with increased number at low numbers (1-10). This positive dependence on initial termite number, at low initial number only, is called an Allee effect (Crawley, 1998) and is particularly interesting when compared to a study by Lenz and William [15], which showed low termite numbers of Coptotermes and Nasutitermes species to give low survival. The total number of termite workers of $R$ Santonensis at the lowest initial termite number ( 5 ) were used by ( Laetitia \& Wright, 2002), but termite workers could not survive, which may be explained by the fact that the termite numbers were too few to combat colonisation by fungi or other pathogens( Becker,[14 ] or to maintain optimum humidity Gay et al; [170]. Alternatively, five individuals may be too few to form a functional colony. While proportion survival was higher in the second experiment, it may be that these small colonies may be less vigorous and therefore less able to establish Lenz \& William, [15]. Termites are social insects and require the presence of several other individuals to be able to thrive Grasse \& Chauvin, [169]; Gay et al; [170].

The decrease in survival at the highest initial termite numbers in the experiment may be explained by over- crowding and hence high levels of cannibalism due to limited food resources such as moisture. Crowding in small containers is said to offset the advantage of a larger group (Light \& Ill, 1945). The number of termites used in the experiments was a compromise between available resources and what was judged to be a reasonable colony size. Density effects may be specific to the experimental methods used, e.g. container size and matrix used Lenz \& William, [15]. Thus, the same must be true in a natural situation and experiments performed to date have not used volumes large enough to make a suitable comparison to the field situation. Comparing with other sympatric species of the genus Reticulitermes, $R$ Grassei UK showed a greater level of survival compared to R Santonensis yet in the French strains, this was inverted, $R$ Santonensis France showing the greater survival ( Laetitia \& Wright, 2002). The latter is in agreement with previous observations that $\mathrm{R}$ Santonensis is the most robust species Feytaud, [171]; Grasse, [164]; Jacquiot, [172]; Becker, [8] although these were purely field observations and had no experimental proof. This could however, suggest that the population of $R$ Grassei that established in Devon was a more robust population and thus was more easily able to establish or alternatively, had developed a greater robustness during its development in the UK. Perhaps both factors could play a role in its increased ability to survive. Natural geographical distribution of Reticulitermes species in Europe is represented in (Figures $1 \& 2$ ).

\section{Termiticide Bioassays}

One of the reasons why nicotine analog and chitin synthesis inhibitors can eliminate colonies of subterranean termites is their slow mode of action. This allows these toxicants to be distributed broadly within a colony, as has been demonstrated both in thiamethoxam and hexaflumuron in the present study. Su [62], Su et al. [69], Grace et al. [135], and Su and Scheffrahn [66] indicate that hexaflumuron when tested in the field at $5000 \mathrm{ppm}$, nonrepellent and have a slow mode of action. Su et al. [173] and Su and Scherer [174] have revealed that slow acting bait toxicants are taken up by a large proportion of termite while they randomly visit their foraging sites and transfer active ingredient among nestmates through trophallaxis Sheet et al. [76], Suarez and Thorne [175] until the amount taken by an individual termite reaches the lethal dose level. Among the bait toxicants speed of action against a certain species of termite varies Su and Scheffrahn [60,64], Karr et al. [27].

Recent laboratory studies and field tests have shown the high activity of hexaflumuron against subterranean termites Reticulitermes and Coptotermes Su [62]; Su [66]. These species are lower termites, on which hexaflumuron may act not only on larvae but also on workers as these forms may undergo many moults after their differentiation. Grasse (1982). Previous studies on the use of Imidacloprid against different termite species showed that, Imidacloprid is an insecticide exhibiting low mammalian toxicity. It acts on the insect nervous system by attaching to the acetylcholine binding sites, called nicotinergic receptors, on receiving nerve cells Abbink [49]. This mode of action prevents transmission of information at these binding sites, leading to a lasting impairment of the nervous system and eventually death of the insect Schroeder and Flattum [50].Mammals have few nicotinergic receptors; thus, 
imidacloprid has very low mammalian toxicity Sattelle et al. [51]. Imidacloprid, a nicotine analog, is an insect-specific agonist of nicotinic acetylcholine receptors that has been reported to be nonrepellent to termites Matsuda et al. [54], Thorne and Breisch [42].Because of their non repellency and apparent delayed action, it has been suggested that, unlike the repellent pyrethroid or fastacting organic phosphate termiticides, these new termiticides may impact the subterranean termite populations Kard [176], Potter and Hillery [45], Wagner [46], Hu [34]. Laboratory study indicated that termites exposed to sublethal doses of imidacloprid did not show aversion to the subsequent exposure and may continue to travel through the treated soil, resulting in the colony suppression Thorne and Breisch [42].

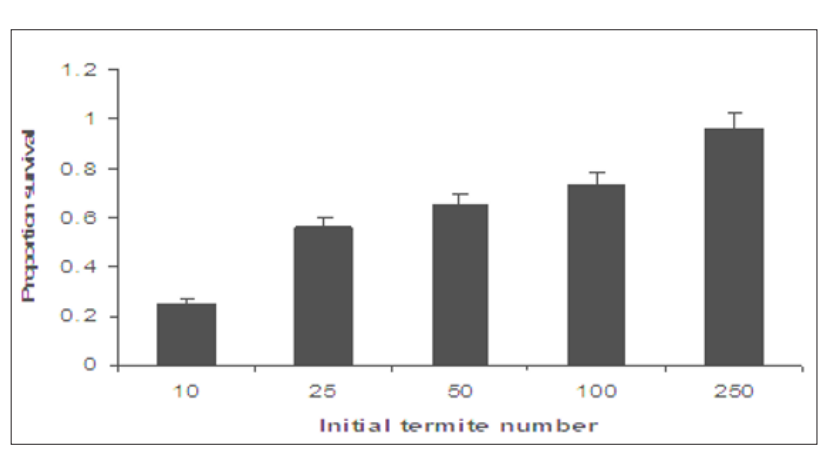

Figure 3: Mean proportion survival (खSE) of R. Santonensis in the laboratory after 28 weeks as a function of initial termite number $(n=4)$.

Movement of exposed termites also may spread the nonrepellent toxicants to nestmates through trophallaxis and social grooming Ibrahim et al. [48], $\mathrm{Hu}$ [34]. Evidence is accumulating to show that the active ingredient of Premise $\AA$, imidacloprid, is transferred between individual termites Thorne and Breisch [42]; Shelton and Grace [39]; Tomalski and Vargo [177] and that effects can be far reaching beyond the treatment area Osbrink and Lax [23]. Our results using Imidacloprid against $R$ Santonensis at different concentrations $(0.3,1,3,10,100$ and $300 \mathrm{ppm})$ showed that at, $300 \mathrm{ppm}$ termite mortality was $100 \%$, signifying the enormous practical concentration to be effective in eliminating $R$ Santonensis in the laboratory conditions. This finding further necessitates the use in the field conditions as well as against other Reticulitermes spp. In general, mortality increased with the increase of all concentrations tested against R. santonensis. These results indicate that concentration has considerable impact on mortalty (Figure 3) Long term monitoring and application of Imidacloprid both in laboratory and field condition against a wide range of termite species is necessary. This will provide a rigorous assessment of colony elimination by imidacloprid treatment. In our study comparative efficacy of three bait toxicants i.e., thiamethoxam, hexaflumuron and Imidacloprid was evaluated against the subterranean termite species R. santonensis. Based on their LC50 values, ranging from $2.41,3.15$ and 202.3 ppm respectively, indicate the order of their toxicity. Similarly long term bioassay results using thiamehoxam at $(0.1,2.5 \mathrm{ppm})$ and hexaflumuron at $(10,200 \mathrm{ppm})$ suggest that both thiamethoxam and hexaflumuron are efficient in termite control, because thiamethoxam showed a significant mortality ranged from $93-95.7 \%$, whereas hexaflumuron provoked 76.7-92.1\% mortality over a period of 12 weeks. Based on these results it's quite clear that, thiamethoxam is more toxic and faster in action than Imidacloprid followed by hexaflumuron at all treatment concentrations.

\section{No Choice Feeding Bioassay}

In our no-choice feeding bioassay, termites that had been exposed to paper bait treated with thiamethoxam were killed showed a faster action at $100 \mathrm{ppm}$ with $100 \%$ mortality after 3 weeks when compared hexaflumuron, mortality was $90 \%$ at $1000 \mathrm{ppm}$. The feeding deterrent effects of bait toxicants are also important. The amount of paper ingested by termite workers in tests decreased as expected when the concentrations of both thiamethoxam and hexaflumuron increased. The weight loss for thiamethoxam or hexaflumuron treated paper ranged from 12$17.5 \%$ occurred even at the highest concentrations (100 and $1000 \mathrm{pppm}$ ), indicating that this feeding was adequate to cause significant termite mortality (90-100\%). This might be due to the speed of action or probably, any feeding deterrent effects of both toxicants, because treated filter paper baits were the only available food for termites under no choice conditions. Previous studies on thiamethoxam have also reported the non-repellent, quick mode of action and anti-feedant behaviour against other species of termites.

The notable researchers work include, Delgrade et al. [178] who reported the effects of thiamethoxam on three species of African termite crop pests: Trinervitermes trinervius Rambur, Odontotermes smeathmani Fuller and Amitermes evuncifer Silvestri, and suggested the dose range from 0.3 to $10 \mathrm{ppm}$ resulted in $100 \%$ mortality within 2- 8 days, furthermore, proved to be an anti-feedant but not repellent. Declines in dry wood termite feeding behavior 30-days after treatment have been reported from laboratory studies using thiamethoxam and field studies using other active ingredients (Lewis and Power 2004; Scheffrahn et al., [179]; Ferster et al. 2001). Lewis et al. (2005) both lab and field results suggest thiamethoxam is non-repellent, has a quick mode of action. Our results using thiamethoxam are in agreement with previous observations and suggest that thiamethoxam has quick mode of action, non-repellent and some degrees of anti-feedant against the workers of R. santonensis. Some previous literature on different termite species reflects the efficacy of the hexaflumuron, and some researchers reported the effects both under laboratory and field conditions. For example, Haagsma and Rust [180] reported the effects of hexaflumuron consumption on the mortality of workers of the Western subterranean termite, Reticulitermes Hesperus Banks, and observed that the onset of mortality began at day 8 , with cumulative mortality reaching approximately $96 \%$ by day 45 . In our study on $R$ Santonensis the cumulative mortality reaching $90 \%$ by day 21 . Which is in agreement with the Haagsma et al. (2005) findings, although, the mortality in both case was significant as in Reticulitermes Hesperus Banks and R Santonensis. But this slight difference in mortality might be resulted due to 
environmental conditions in the laboratory, the size of the bait, baits acceptability and proportion of the population size. Yoshinobu et al.(2000) in their preliminary findings strongly supported the applicability of hexaflumuron to the control of $R$. Speratus due to little dose dependence and feeding deterrence of the chemical. Ours results are in consistent with the previous observations in terms of significant mortality, little dose dependence (Figures 4 \& 5) slow action and some degree of feeding deterrence. Further studies, however, are needed to examine its slow-acting property against wide range of termite species that is essential as a bait toxicant.

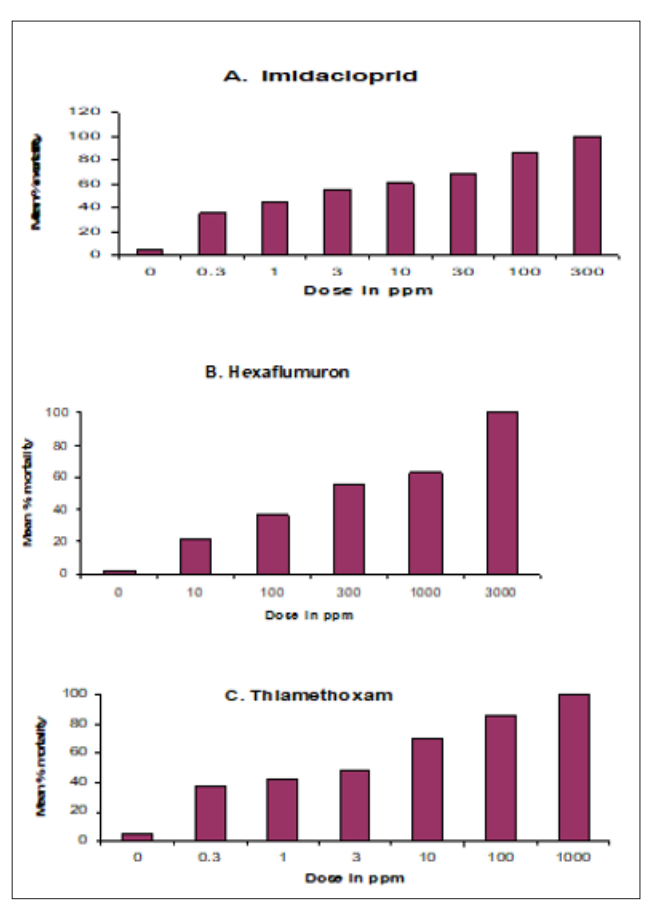

Figure 4: Mean\% mortality of R. Santonensis when treated with different doses of imidacloprid, Hexaflumuron and Thiamethoxam.

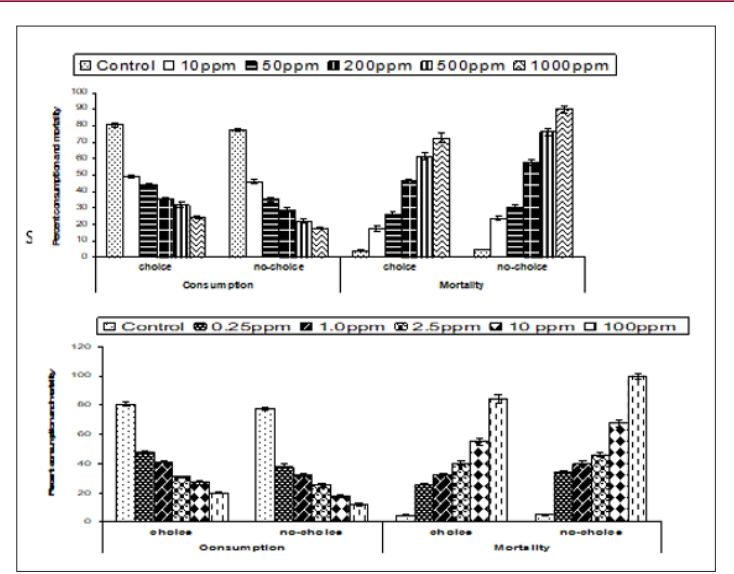

Figure 5: Means $( \pm S E)$ of $R$ Santonensis consumption (milligram) and mortality under Choice and no Choice (percentage) in response to filter paper treated with hexaflumuron (above) and Thiamethoxam (below) after 3 weeks.

\section{Choice Feeding Bioassay}

In the choice test, consumption of the treated paper bait generally decreased compared with untreated paper baits for both thiamethoxam or hexaflumuron at all concentrations tested , regardless of the time elapsed after the initiation of the test. Moreover, the amount of treated paper baits with thiamethoxam or hexaflumuron consumed at 100 and 1000 ppm did not differ significantly after 3 weeks, which seemed to reflect reluctance to feed within 3 weeks. A small amount of feeding of treated paper with thiamethoxam and hexaflumuron (15-19\% paper wt. loss) occurred even at the highest concentrations tested (100pp and $1000 \mathrm{ppm})$, and this feeding was sufficient to cause significant termite mortality (90-100\%) even though an alternative food source was available to the termite workers.

The results demonstrated that feeding deterrence occurred at 100 for thiamethoxam and at $1000 \mathrm{ppm}$ for hexaflumuron. However, large fluctuations in the concentrations that caused feeding deterrence in $R$ Santonensis in the choice test may have several possible explanations, but true case has not yet been determined. These findings suggest that the bait matrix should be carefully chosen to contribute to the more efficient uptake of bait toxicants and the faster elimination of termite colonies. Simultaneously, the time required for colony elimination depends on the proportion of termites that are infected with slow acting toxicants. The relation between the amount of active ingredients taken by termites and the decline in their activity should also be quantitatively investigated both in the laboratory and the field. This suggests that, field trials are required with the same level of treatment with a single application of thiamethoxam or hexaflumuron to assess efficacy against $R$ Santonensis colonies in particular, and other species of the Reticulitermes in general without eliminating them. A combination of speed of action, transferability of active ingredients among nestmates through trophallaxis and lethal dose/dose dependence is the answer for efficient suppression or elimination of the termite colonies. The current results showed that paper baits treated with $100 \mathrm{ppm}$ thiamethoxam, and $1000 \mathrm{ppm}$ hexaflumuron selected as a likely practical use concentration, resulted in significant termite mortality 3 weeks after initial treatment, but induced no significant mortality compared with untreated controls, after 3 weeks. The mortality induced by 1000 ppm hexaflumuron indicating relatively slow acting nature even at high concentrations. However, in spite of this, hexaflumuron is still effective bait because of its slow acting nature. As hexaflumuron has a mean half-life of 9 days before it is cleared from the body, so termites have time to spread the toxicant to unexposed nest mates $\mathrm{Su}$ et al. [82]. Hexaflumuron is not easily metabolised by termites Sheet et al. [76]. The unaltered hexaflumuron can still be transferred to other termites by trophallxis, faeces and cannibalism of the toxic individual Sheet et al. [76]. In the feeding bioassays, $R$ Santonensis consumed treated bait papers to various degrees on different concentrations for thiamethoxam and hexaflumuron suggesting that these bait toxicants were non-repellent to this species. 


\section{Conclusion}

The findings of the results suggest that minimum initial termite number required establishing a successful mini colony is 250 . Future work with more colonies over both smaller and bigger spatial scales will enable us to advance our knowledge of the behaviour and adaptation of $R$ Santonensis. Furthermore, the results obtained from these findings will aid with further risk assessment in the UK and enable potential hotspots in the UK to be tagged. The risk posed by termites in natural areas such as forest is much lower although still present in regions which share common environmental conditions (e.g. temperature) to those where termites are common. Despite the Devon infestation, the higher risk seems to be from $R$ Santonensis due to its more northerly distribution in France and its common association with urban areas. The field trials will be the first of their kind and may help to extrapolate from previously published laboratory data as well as the data produced in this study. Termites may become more of a threat in the UK as the world climate changes due to global warming.

The present study highlights future work on the biology of other species of the genus Reticulitermes for better understanding of their behaviour to develop the effective management strategies. Based on these findings, the significance of bait toxicants for subterranean termite control is the radical reduction of pesticide use as also documented by (LaFage, 1986). This means that, the reduction in pesticide use by itself represents a benefit to both the public at large and to the environment, in particular. These bioassays can be applied under field conditions to assess the feeding preferences of other Reticulitermes spp. and to evolve effective and environmentally friendly control strategies. These results demonstrate that Imidacloprid, Thiamethoxam and hexaflumuron have shown excellent termiticidal efficacy against workers of R. santonensis. The results also demonstrate that hexaflumuron has a relatively slow speed of action together with tremendous termiticidal efficacy against $R$ Santonensis, as shown in the present work on long term bioassays lasted over 12 weeks signifying, that an enormous potential to be effective in termite baiting programs. Ours results are also in consistent with the previous observations in terms of significant mortality, little dose dependence, slow action and some degree of feeding deterrence. Further studies on hexaflumuron, however, are needed to examine its slow-acting property against wide range of termite species that is essential as a bait toxicant. Our results using thiamethoxam are in agreement with previous observations and suggest that thiamethoxam has quick mode of action, non-repellent and some degrees of anti-feedant against the workers of $R$. santonensis. Besides, thiamethoxam has relatively fast speed of action with excellent termiticidal efficacy, indicating that this chemistry has great potential to be highly effective in termite baiting practices. To accomplish this target, further laboratory and field studies are needed.

\section{The Future of Subterranean Termite Control}

Safer and more effective barrier techniques such as physical barriers Lewis et al. [181] or pyrethroid-impregnated polymer barriers (N.-Y. Su, unpublished data) may replace the current liquid insecticides for soil treatment in the future. These barriers may be installed before building construction to supplement the monitoringbaiting programme and further reduce termites' damage potential. Because manual monitoring is the major component of the current monitoring-baiting system and because the industry is uncertain how to pass on this labor cost to the consumers, the system is currently more expensive than conventional soil treatments. As the industry becomes more aware of the financial benefit and the operation of colony elimination, the costs should decrease. Technological development, such as the acoustic emission device Scheffrahn et al. [70, 182-184], will further increase monitoring efficacy and reduce costs. Above ground bait stations, which are to be placed directly over the active termite infestation found in the structures, will provide another tool for the introduction of bait into termite colonies Su et al. [70]. Studies on feeding stimulants Chen and Henderson [185] and semi chemicals associated with foraging behaviour Rust et al. [186] and food searching behaviour Robson et al. [187-188] will improve the efficacy of baiting techniques.

To manage subterranean termite populations better, however, the factors affecting the population dynamics of these cryptic and poorly understood insects need to be studied. A monitoring-baiting programme (both in-ground and above-ground) incorporating a computerized data management system such as Prolinx1 may become a focal point for future IPM for subterranean termites [189220]. Optionally, other control tools, such as barriers, the localized application of liquid or foam termiticides, building modifications, cultural practices, etc., may be integrated into the programme as needed. The information collected from the data management system can be used to dictate station placement, improve monitoring efficiency, predict bait requirement or to suggest other optional control tools at different regions and under various environmental conditions. Using feedback from the database, the integrated programmes may become a self-improving system that continuously enhances its cost-effectiveness. IPM is still in its infancy for the termite control industry. Various definitions of termite IPM are mushrooming from every corner of the industry and reflect a state of confusion on this subject. An IPM programme for subterranean termites needs to provide cost-effective protection of a homeowner's property. The pest control industry and neutral parties, such as the extension service or building inspectors, need to be better trained so that accurate information can be disseminated to homeowners. The final decision for a proper control programme needs to be made by educated consumers. If consumers are fully aware of their options and the costs and benefits of each option, the grass-root demand should shape an IPM programme for the termite control industry.

\section{References}

1. Clement JL, Bagneres AG, Uva P, Wilfert L, Quintana A (2001) Biosystematics of Reticulitermes termites in Europe: morphological, chemical and molecular data. Insectes soc 48(3): 202-215.

2. Lohou C, Burban G, Clément JL, Jequel M, Leca JL (1997) Protection of alignment trees against underground termites. The experience in Paris. Phytoma 492: 42-44. 
3. Clement JL (1986) Open and closed societies in termites of the genus Reticulitermes, geographic variations and seasonality. Sociobiology 11 : 311-323.

4. Clement JL, Lange C (1984) Variation of cuticular compounds and inter and intraspecific aggressive behavior in termite species of the Genus Reticulitermes. Proc. 17 ${ }^{\text {th }}$ Int. Congress of Entomol. Behavior pp. 447.

5. Pearce MJ (1997) Termites: Biology and Pest Manage- ment. CAB International, London, UK.

6. Hickin NE (1971) Termites: A world problem. Hutchinson, London, UK, pp. 232.

7. Su NY, Scheffrahn RH (1990) Economically important termites in the United States and their control. Sociobiology 17: 77-94.

8. Becker G (1969) Rearing of termites and testing methods used in the laboratory. In: Krishna K, Weesner FM (Eds.). Biology of termites, Academic Press, London, UK, 1: 351-385.

9.Noirot CH, C Noirot Timothee (1969) The Digestive System, In: K Krishna, FM Weesner (Eds.). Biology of termites, vol. I. Academic Press, NY, USA, p. 49-88.

10. Thorne BL, BT Forschler (1998) NPCA Research Report on Subterranean Termites. National Pest Control Association, Dunn Loring, VA.

11. Jacquiot C (1955) The Paris colonies of Saintonge termite. The Rev Wood 10: 12 .

12. Serment MM, Tourteaux 0 (1991) Les termites. CTBA Brochure ISSN 0528-4929.

13. Sen Sarma PK (1994) Accelerated anti-termite laboratory tests, simulation of field conditions and assessment of results for service life. International Research Group on wood Preservation. pp. 94-20034.

14. Becker G (1969) Termites as laboratory insects. in Termite Symposium, British wood Preservation Association p. 81-94.

Lenz M, ER Williams (1980) Influence of container, matrix volume and group size on survival and feeding activity in species of Coptotermes and Nasutitermes (Isopteraa: Rhinotermitidae; Termitidae). Material and Organismen. 15(1): 25-46.

15. Nutting WL (1969) Flight and colony foundation. In: K Krishna \& FM Weesner (Eds.). Biology of termites, v.1. Academic Press, New York, USA, pp. 233-282.

16. Deitz LL, Nalepa C, Klass KD (2003) Phylogeny of the Dictyoptera reexamined (Insecta). Entomologische Abhandlungen (Dresden) 61: 6991.

17. Noirot C (1992) From wood- to humus-feeding: an important trend in termite evolution. Biology and Evolution of Social Insects. In: J Billen (Eds.). Leuven University Press, Leuven, Belgium, pp. 107-119.

18. Abe T, Bignell DE, Higashi M (2000) Termites: evolution, sociality, symbiosis, ecology. Kluwer, Dordrecht.

19. Abe TF, Hyodo T, Inoue JI, Azuma I, Tayasu (2000) Role of the mutualistic fungus in lignin degradation in the fungus-growing termite Macrotermes gilvus (Isoptera; Macrotermitinae). Soil Biology \& Biochemistry 32(5): 653-658.

20. Potter MF (2004) Termites. In: SA Hedges (Eds.), Handbook of Pest Control, $9^{\text {th }}($ edn). GIE Media, Inc, Cleveland, OH, pp. 216-361.

21. Su NY, RH Scheffrahn (1998) A review of subterranean termite contro practices and prospects for integrated pest management programmes. Integrated Pest Management Reviews 3: 1-13.

22. Lax AR, LA Osbrink (2003) United States Department of AgricultureAgriculture Research Service research on targeted management of the Formosan subterranean termite Coptotermes formosanus Shiraki (Isoptera: Rhinotermitidae). Pest Manage Sci 59 (6): 788-800.

23. Getty GM, MI Haverty, VR Lewis (2000) Agonistic behavior between recent collections and laboratory cultures of Reticulitermes (Isoptera:
Rhinotermitidae) from northern California. Pan-Pac. Entomol. 76(4): 243-250.

24. Getty GM, Haverty MI, Copren KA, Lewis VR (2000) Response of Reticulitermes spp. (Isoptera: Rhinotermitidae) in northern california to baiting with hexaflumuron with sentricon termite colony elimination system.). J Econ Entomol 93(5): 1498-1507.

25. Haagsma K, J Bean (1998) Evaluation of a hexaflumuron- based bait to control subterranean termites in southern California (Isoptera: Rhinotermitidae). Sociobiology 31: 363-369.

26. Karr LL, Sheets JJ, King JE, Dripps JE (2004) Laboratory performance and pharmacokinetics of the benzoylphenylurea noviflumuron in Eastern subterranean termites (Isoptera: Rhinotermitidae). J Econ Entomol 97(2): 593-600.

27. Lewis R, J Ballard, G Cramer (1998) Systematic Termite Control...Results In The Real World, In Proceedings of the National Conference on Urban Entomology, San Diego, CA, pp. 109-112.

28. Potter MF (1997) Termite baits: a status report. Pest Control Technol. 25: 24-26.

29. Curl G (2004) Pumped-up termite market. Pest Control Technol 32: 26.

30. Anonymous (2002) Environmental fate of Imodacloprid. Pflanzenschutz Nachrichten Bayer 55, Special Edition. Bayer Crop Sciences AG.

31. Beeman RW (1982) Recent advances in mode of action of insecticides. Annu Rev Entomol 27: 253-281.

32. De Mark JJ, Benson EP, Zungoli PA, Kard BM (1995) Evaluation of hexaflumuron for termite control in the southeast U.S. Down to Earth 50: 206 .

33. Hu XP (2005) Evaluation of efpcacy and nonrepellency of indoxacarb and fipronil-treated soil at various concentrations and thickness against two subterranean termites (Isoptera: Rhinotermitidae). J Econ Entomol 98(2): 509-517.

34. Su NY, RH Scheffrahn (1990) Potential of insect growth regulators as termiticides: A review. Sociobiology 17(2): 313-328.

35. Quarles W (1995) New technologies in termite control. The IPM Practitioner XVII: 1-9.

36. Gold RE, HN Howell, BM Pawson, MS Wright, JC Lutz (1996) Persistence and bioavailability of termiticides to subterranean termites (Isoptera: Rhinotermitidae) from five soil types and locations in Texas. Sociobiol 28: $337-364$

37. Henderson G, Sharpe Mc Collum K, Dunaway C (1998) Subterranean termite (Isoptera: Rhinotermitidae) attack on ground monitors around an apartment complex in fixed pattern placement versus conducive placements Fla Entomol 81(3): 461-464

38. Shelton TG, JK Grace (2003) Effects of exposure duration on transfer on nonrepellent termiticides among workers of Coptotermes formosanus Shiraki (Isoptera: Rhinotermitidae). J Econ Entomol 96(2): 456-460

39. Verkerk RHJ, AF Bravery (2001) The UK termite eradication programme: justification and implementation.Sociobiology 37: 351-360.

40. Gahlhoff J, Koehler PG (2001) Penetration of the eastern subterranean termite into soil treated at various thicknesses and concentrations of Dursban TC and Premise 75. J Econ Entomol 94(2): 486-491.

41.Thorne BL, Breisch NL (2001) Effects of sublethal exposure to imidacloprid on subsequent behaviour of subterranean termite Reticulitermes virginicus (Isoptera: Rhinotermitidae). J Econ Entomol 94(2): 492- 498.

42.Dergarde S, Rouland Lefevre C (2002) Evaluation of the effects of thiamethoxam on three species of African termite (Isoptera: Rhinotermitidae) crop pest. J Econ Entomol 95(3): 531-536.

43.De Mark JJ, Benson EP, Zungoli PA, Kard BM (1995) Evaluation of hexaflumuron for termite control in the southeast U.S. Down to Earth 50: 206. 
44. Potter MH, AE Hillery (2002) Exterior-targeted liquid termiticides: an alternative approach to managing subterranean termites (Isoptera: Rhinotermitidae) in buildings. Sociobiology 39(3): 373-405.

45. Wagner T (2003) US Forest Service termiticide tests. Sociobiology 41(1): 131-141.Thorne BL, Breisch NL (2001) Effects of sublethal exposure to imidacloprid on subsequent behavior of subterranean termite Reticulitermes virginicus (Isoptera: Rhinotermitidae). J Econ Entomol 94: 492-498.

46.Thorne BL, Breisch NL (2001) Effects of sublethal exposure to imidacloprid on subsequent behaviour of subterranean termite Reticulitermes virginicus (Isoptera: Rhinotermitidae). J Econ Entomol 94(2): 492- 498.

47. Ibrahim SA, G Henderson, H Fei (2003) Toxicity, repellency, and horizontal transmission of fipronil in the Formosan subterranean termite (Isoptera: Rhinotermitidae). J Econ Entomol 96(2): 461-467.

48. Abbink J (1992) The biochemistry of imidacloprid. PflanzenschutzNachr. Bayer 44: 183-195.

49. Schroeder ME, RF Flattum (1984) The mode of action and neurotoxic properties of the nitromethylene heterocycle insecticides. Pest. Biochem. Physiol 22(2): 148-160.

50. Sattelle DB, SD Buckingham, KA Wafford, SM Sherby, NM Bakry, et al. (1989) Actions of the insecticide 2 (Nitromethylene tetrahydro-1, 3-thiazine) on insect and vertebrate nicotinic acetylcholine receptors. Proc R Soc Lon B 237(1289): 501-514.

51. Pawson BM, RE Gold (1996) Evaluation of baits for termites (Isoptera: Rhinotermitidae) in Texas. Sociobiol. 28: 485-510.

52. Potter MF, EA Eliason, K Davis (2001) Targeting termites. Pest Control Tech. 29: 58-60.

53. Matsuda K, SD Buckingham, D Kleier, JJ Rauh, M Grauso, et al. (2001) Neonicotinoids: insecticides acting on insect nicotinic acetylcholine receptors. Trends Pharmacol Sci 22(11): 573-580.

54. Esenther GR, Gray DE (1968) Subterranean termite studies in southern Ontario Can Entomol. 100(8): 827-834.

55. Beard RL (1974) Termite biology and the bait-block method of control. Connecticut Agriculture Experiment Station Bulletin 748. New Haven, Connecticut, p. 12.

56. Esenther GR, Beal RH (1974) Attractant-mirex bait suppresses activity of Reticulitermes spp. J Econ Entomol 67(1): 85-88.

57. Esenther GR, Beal RH (1978) Insecticidal baits on field plot perimeters suppress Reticulitermes. J Econ Entomol 71: 604-607.

58. Su NY (1991) Evaluation of bait-toxicants for suppression of subterranean termite population. Sociobiol. 19: 211-220.

59. Scheffrahn RH, Robbins WP, Busey P, Su NY, Mueller RK (1993) Evaluation of a novel, hand-held, acoustic emissions detector to monitor termites (Isoptera: Kalotermitidae, Rhinotermitidae) in wood. Journal of economic entomology 86(6): 1720-1729.

60. Rojas MG, JA Morales Ramos (2001) Bait matrix for delivery of chitin synthesis inhibitors to the Formosan subterranean termite (Isoptera: Rhinotermitidae). J Econ Entomol 94(2): 506-510.

61. Su NY (1994) Field evaluation of hexaflumuron bait for population suppression of subterranean termites (Isoptera: Rhinotermitidae). J Econ Entomol 87(2): 389-397.

62. Beeman RW (1982) Recent advances in mode of action of insecticides. Annu Rev Entomol 27: 253-281.

63. Su NY, RH Scheffrahn (1996) A review of the evaluation criteria for bait- toxicant efficacy against field colonies of subterranean termites (Isoptera). Sociobiol 28: 521-530.

64. Su NY, RH Scheffrahn (1993) Laboratory evaluation of two chitin synthesis inhibitors, hexaflumuron and diflubenzuron, as bait toxicants against Formosan and eastern subterranean termites (Isoptera: Rhintotermitidae). J Econ Entomol 86: 1453-1457.

65. Su NY, RH Scheffrahn (1996) Comparative effects of two chitin synthesis inhibitors, hexaflumuron and lufenuron, in a bait matrix against subterranean termites (Isoptera: Rhinotermitidae) J Econ Entomol 89: $1156-1160$

66. Kistner DH, Sbragia RJ (2001) The use of the Sentricon Termite Colony Elimination System for controlling termites in difficult control sites in northern California. Sociobiol 37(2): 265-280.

67. Chambers DM, Benson EP (1995) Evaluation of hexaflumuron for protection of structures from termites in New Orleans. Down to Earth 50: 27-31.

68. Robertson AS, NY Su (1995) Discovery of an effective slow-acting growth regulator for controlling subterranean termites. Down to Earth 53: 1-7.

69. Su NY, PM Ban, RH Scheffrahn (1997) Remedial baiting with hexaflumuron in above-ground stations to control structure-infesting populations of the Formosan subterranean termite (Isoptera: Rhinotermitidae). J Econ Entomol 90(3): 809-817.

71.Atkinson TH, Smith MS, Williams RE (1998) Control structural infestations of Heterotermes aureus in Arizona with the sentricon system. Down to Earth 53: 18-25.

72. Tsunoda K, H Matsuoka, T Yoshimura (1998) Colony Elimination of Reticulitermes speratus by bait application and the effect on foraging territory. J Econ Entomol 91(6): 1383-1386.

73. Peters BC, CJ Fitzgerald (1999) Field evaluation of the effectiveness of three timber species as bait stakes and the bait toxicant hexaflumuron in eradicating Coptotermes acinaciformis (Froggatt) (Isoptera: Rhinotermitidae). Sociobiology 33(3): 227-238.

74. Prabhakaran SK (2001) Eastern subterranean termite management using baits containing hexaflumuron in affected University of Iowa structures (Isoptera: Rhinotermitidae). Sociobiology 37(1): 221-233.

75. Su NY, RH Scheffrahn (1988) Foraging population and territory of the Formosan subterranean termite (Isoptera: Rhinotermitidae) in an urban environment. Sociobiology 14: 353-359.

76. Sheets JJ, LL Karr, JE Dripps (2000) Kinetics of uptake, clearance, transfer, and metabolism of hexaflumuron by eastern subterranean termites (Isoptera: Rhinotermitidae). J Econ Entomol 93(3): 871-877.

77. Grace JK, NY Su (2001) Evidence supporting the use of termite baiting systems for long-term structural protection (Isoptera). Sociobiology 37(2): 301-310.

78. Alles SM, PG Koehler (1997) Insecticides used in the urban environment: mode of action. University of Florida Cooperative Extension Service, Institute of Food and Agricultural Sciences. FS \# ENY-282.

79. Su NY, RH Scheffrahn (1991) Laboratory evaluation of two slowacting toxicants against Formosan and Eastern subterranean termites (Isoptera: Rhinotermitidae) J Econ Entomol 84(1): 170-175.

80. Paton R, LR Miller (1980) Control of Mastotermes darwiniensis Froggatt (Isoptera: Mastotermitidae) with mirex baits. Aust. For Res 10(3): 249258.

81. Su NY, M Tamashiro, JR Yates, MI Haverty (1982) Effect of behaviour on the evaluation of insecticides for prevention of or remedial control of the Formosan subterranean termite. J Econ Entomol 75(2): 188-193.

82. Su NY, M Tamashiro, MI Haverty (1987) Characterization of slow-acting insecticides for remedial control of the Formosan subterranean termite (Isoptera: Rhinotermitidae). J Econ Entomol 80(1): 1-4.

83. Su NY, RH Scheffrahn (1988) A review of subterranean termite control practices and prospects for integrated pest management programs. Integrated Pest Management Reviews. 3(1): 1-13.

84. Lüscher M (1969) The importance of juvenile hormone for the differentiation of soldiers in termite Kalotermes flavicollis. Proc. 6. 
Contr. Command, Switzerland, pp. 165-170.

85. Haverty MI (1979) Selection of tunnelling substrates for laboratory studies with three subterranean termite species. Sociobiology 4(3): 315-320.

86. Jones SC (1984) Evaluation of two insect growth regulators for the bait-block method of subterranean termite (Isoptera: Rhinotermitidae) control. J Econ Entomol 77(5): 1086-1091.

87. Su NY, M Tamashiro, MI Haverty (1985) Effects of three insect growth regulators, feeding substrates, and colony origin on survival and presoldier production of the Formosan subterranean termite (Isoptera: Rhinotermitidae) J Econ Entomol 78(6): 1259-1263.

88. Su NY, RH Scheffrahn (1989) Comparative effects of an insect growth regulator, S-31183, against the Formosan subterranean termite and eastern subterranean termite (Isoptera: Rhinotermitidae). J Econ Entomol 82(4): 1125-1129.

89. Hrdy I, J Krecek (1972) Development of superfluous soldiers induced by juvenile hormone analogues in the termite, Reticulitermes lucifugus santonensis. Insectes Sociaux 19(2): 105-109.

90. Haverty MI (1977) The proportion of soldiers in termite colonies: a list and bibliography (Isoptera). Sociobiology 2: 199-216.

91. Ware GW (1991) Fundamentals of Pesticides-A Self-Instruction Guide, ( $3^{\text {rd }}$ Edn) Thomson Publications, Fresno, CA.

92. Ware GW (1994) The Pesticide Book. 4th ed. Thomson Publications, Fresno, CA.

93. Ishaaya I (1990) Benzoylphenyl ureas and other selective insect control agents- mechanism and application, pp. 365-376.

94. Mulder R, MT Gijswijt (1973) The laboratory evaluation of two promising new insecticides which interfere with cuticle deposition. Pestic Sci 4(5): 737-745.

95. Ascher KRS, Nemny NE (1974) The ovicidial effect of PH 60-40 [1-(4chlorophenyl)-3-(2,6-difluorobenzyl)-urea] in Spodoptera littoralis Boisd. Phytoparasitica 2(2): 131-133.

96. Sarasua MJ and C Santiago Alvarez (1983) Effects of diflubenzuron on the fecundity of Ceratitis capitata. Entomol. Exp. Appl 33(2): 223-225.

97. Muzzarelli R (1986) Chitin synthesis inhibitors: effects on insects and on non-target organisms. Crit. Rev Environ Control 16(2): 141-146.

98. Marco V, G Perez Farinos, P Castañera (1998) Effects of hexaflumuron on transovarial, ovicidal, and progeny development of Aubeonymus mariaefranciscae (Coleoptera: Curculionidae). Environ Entomol 27: 812816.

99. Granett J (1987) Potential of benzoylphenyl ureas in integrated pest management. Chitin and Benzoylphenyl Ureas pp. 283-302.

100. Horowitz AR, M Klein, S Yablonski, I Ishaaya (1992) Evaluation of benzoylphenyl ureas of controlling the spiny bollworm, Earias in Scheffrahn lana (Boisd), in cotton. Crop Protection 11(5): 465-469.

101. Verloop A, CD Ferrall (1977) Pesticide Chemistry in the $20^{\text {th }}$ Century, In: JR Plimmer (Eds.), ACS Symposium Series No. 37. American Chemical Society, Washington DC, USA, pp. 237- 70.

102. Su NY, RH Scheffrahn (1990) Economically important termites in the United States and their control. Sociobiology 17: 77-92.

103. Haverty MI, RW Howard (1979) Effects of insect growth regulators on subterranean termites: induction of differentiation, defaunation, and starvation. Ann Entomol Soc Am 72(4): 503-508.

104. Haverty MI, NY Su, M Tamashiro, R Yamamoto (1989) Concentration dependent presoldier induction and feeding deterrency: potential of two insect growth regulators for remedial control of the Formosan subterranean termite (Isoptera: Rhinotermitidae). J Econ Entomol 82(5): 1370-1374.
105. Howard RW, MI Haverty (1978) Defaunation, mortality and soldier differentiation: concentration effects of methoprene in a termite. Sociobiology 3: 73-77.

106. Howard RW, MI Haverty (1979) Termites and juvenile hormone analogs: a review of methodology and observed effects. Sociobiology 4(2): 269-278.

107. Belda J, Guerrero L (1992) Evaluation of some insecticides against Beet Armyworm (Spodoptera exigua) in watermelon. Tests of agrochemicals and cultivars. Ann Appl Biol 120: 12-13.

108. Komblas KN, P Tsakonas, M Lysandrou, TK Elia (1989) Control of insect pests on fruit and field crops with hexaflumuron in North Greece. Entomologica Hellenica 7: 35-41.

109. Komblas KN, RC Hunter (1986) A benzolyphenyl urea for rational control of pests of pests on fruit and vegetables, In Proceedings British Crop Protection conference- Pests and Diseases, Brighton, London, UK, pp. 907-914.

110. Horowitz AR, M Klein, S Yablonski, I Ishaaya (1992) Evaluation of benzoylphenyl ureas of controlling the spiny bollworm, Earias insulana (Boisd), in cotton. Crop Protection 11(5): 465-469.

111.Ascher KRS, Nemny NE, Blumberg D, Goldenberg S (1986) Egg sterilizing effect of benzoylphenylureas via the adult stage of the nitidulid beetle Caropphilys hemipterus. Phytoparasitica. 14(3): 87-192.

112. Marco V, E Viñuela (1994) Effects of hexaflumuron on fecundity, fertility, and longevity of Phestia kuehniella Zeller and Spodoptera exigua (Hubner). Meded. Vac. Landbouwwet. Univ. Gent 59: 457-463.

113. Sbragia RJ, B Bishabri Ershadi RH Risterink (1983) XRD-473, a newacylurea insecticide effective against Heliothis. 10th Int. Congr. Plant Protection 1: 417-424.

114. Randall M, TC Doody (1934) Poison dusts. I. treatments with poisonous dusts, In: CA. Kofoid (Eds.), Termites and termite control. University of California Press, Berkeley, pp. 463-476.

115. French JRJ, PJ Robinson (1981) Baits for aggregating large numbers of subterranean termites. Australian Journal of Entomology 20(1): 75-76.

116. French JRJ (1991) Baits and foraging behavior of Australian species of Coptotermes. Sociobiology 19: 171-186.

117. Grace JK, JR Yates III, CHM Tome (1995) Modification of a commercial bait station to collect large numbers of subterranean termites (Isoptera: Rhinotermitidae). Sociobiology 26(3): 259-268.

118. Forschler BT, Ryder JC (1996) Subterranean termite colony response to baiting with hexafumuron in Georgia. Down to Earth 15: 30-35.

119. Forschler BT, Ryder JC (1996) Subterranean termite, Reticulitermes spp. (Isoptera: Rhinotermitidae) colony response to baiting with hexaflumuron using a prototype commercial baiting system. J Entomol Sci 31(2): 143-151.

120. Traniello JF, BL Thorne (1994) Termite Baits in Theory and Practice, In: WH Robinson (Eds.), Proceedings of the National Conference on Urban Entomology, Atlanta, GA, pp. 28- 40.

121. Getty GM, MI Haverty, KC Copren, VR Lewis (1999) Seasonal foraging behavior of Reticulitermes spp. (Isoptera: Rhinotermitidae) in northern California, USA, pp. 347-352.

122. Getty GM, MI Haverty, VR Lewis, R. J. Sbragia (1999) Interfacing basic biology of Reticulitermes spp. and the Sentricon Termite Colony Elimination System in northern California, USA, pp. 601-604.

123. Haverty MI, GM Getty, KA Copren, VR Lewis (1999) Seasonal foraging and feeding behavior of Reticulitermes spp. (Isoptera: Rhinotermitidae) in a wildland and a residential location in northern California. Environ Entomol 28(6): 1077-1084.

126. Haverty MI, GM Getty, KA Copren, VR Lewis (2000) Size and dispersion of colonies of Reticulitermes spp. (Isoptera: Rhinotermitidae) in a 
wildland and a residential location in northern California. Environ Entomol 29(2): 241-249.

127. Su NY, RH Scheffrahn (1990) Comparison of eleven soil termiticides against the Formosan subterranean termite and the eastern subterranean termite (Isoptera: Rhinotermitidae). J Econ Entomol 83(5): 1918-1924.

128. Gold RE, HN Howell, EA Jordan III (1993) Horizontal and vertical distribution of chlorpyrifos termiticide applied as liquid or foam emulsions, pp. 140- 155.

129. Su NY (2002) Novel technologies for subterranean termite control Sociobiology 40(1): 95-101.

130. Kofoid CA (1934) Termites and Termite Control. University of California Press, Berkeley, CA.

131. Weesner FM (1965) The Termites of the United States-A Handbook National Pest Control Association, Elizabeth, NJ.

132. Wilson EO (1971) The Termites, pp.103-119; Caste: Termites, In The Insect Societies. The Belknap Press of Harvard University Press. Cambridge, MA, pp. 183-196.

133. Houseman RM, TE Macom, BM Pawson, RE Gold (2000) Seasona feeding depth of the eastern subterranean termite, Reticulitermes flavipes (Kollar) (Isoptera: Rhinotermitidae), pp. 22-23.

134. Macom TE (1999) Factors influencing secondary colony formation in Reticulitermes flavipes (Kollar) and Reticulitermes virginicus (Banks). pp. 240.

135. Myles TG (1999) Review of Secondary Reproduction in Termites (Insecta: Isoptera) with Comments on its Role in Termite Ecology and Social Evolution. Sociobiology 33: 1.

136. Thorne BL, NL Breisch (1996) Colony development and reproductive dynamics in the subterranean termite Reticulitermes flavipes (Kollar), In: AG Appel (Eds.), Proceedings of the National Conference on Urban Entomology, February 18-20, Arlington, TX, pp. 28-29.

137. Cornelius ML, Grace JK (1996) Effect of two ant species (Hymenoptera: Formicidae) on the foraging and survival of the Formosan subterranean termite (Isoptera: Rhinotermitidae). Environ Entomol 25: 85-89.

138. Forschler BT, Henderson G (1995) Subterranean termite behaviora reaction to water and survival of inundation: implications for field populations. Environ Entomol 24(6): 1592-1597.

139. Grace JK, RT Yamamoto, PE Laks (1993) Evaluation of the termite resistance of wood pressure treated with copper naphthenate. Forest Products Journal 43: 72- 75.

140. Jones SC (1989) Field evaluation of fenoxycarb as a bait toxicant for subterranean termite control. Sociobiol 15: 33-41.

141. Kard BM, JK Mauldin, SC Jones (1989) Evaluation of soil termiticides for control of subterranean termites (Isoptera: Rhinotermitidae). Sociobiol 15: 285- 297.

142. Kard BM (1996) Termiticide field tests: 1996 Gulfport update. Pest Control 25: 45-48, 92.

143. Yates JR., III JK Grace, JN Reinhardt (2000) Installation guidelines for the basaltic termite barrier: a particle barrier to Formosan subterranean termites (Isoptera: Rhinotermitidae). Sociobiol 35: 1-16.

144. Schmid Hempel P (1998) Parasites in Social Insects. Princeton University Press, Princeton, NJ.

145. Van Driesche RG, TS Bellows (1996) Pathogens and nematodes of arthropods, and pathogens of vertebrates. P. 66-77. In Biological Control. Chapman \& Hall, New York, USA

146. Wright MS, AR Lax, G Henderson J Chen (2000) Growth response of Metarhizium anisopliae to two Formosan subterranean termite nest volatiles, naphthalene and fenchone. Mycologia 92(1): 42-45.
147. Jones SC, M Lenz (1996) Fenoxycarb-induced caste differentiation and mortality in Coptotermes formosanus (Isoptera: Rhinotermitidae). J Econ Entomol 89(4): 906-914.

148. Ballard JB (1997) Termite baiting 101. Pest Control 65: 30,34,36,40.

149. Su NY (1995) Population control of subterranean termites using a bait matrix containing hexaflumuron. Down to Earth 50: 8-17.

150. Grace JK, CHM Tome, TG Shelton, RJ Oshiro, JR Yates III (1996) Baiting studies and considerations with Coptotermes formosanus (Isoptera: Rhinotermitidae) control in Hawaii. Sociobiol. 28(3): 511-520.

151. Sweeney K (2000) Regulatory perspectives and challenges for termite bait product registration, In: DR Suiter (Eds.), Proceedings of the National Conference on Urban Entomology, May 14-16, 2000, Ft. Lauderdale, FL, p. 20.

152. Buchanan M (2002) Nexus: Small Worlds and the Ground breaking Science of Networks. W. W. Norton and Company, Inc. New York, USA.

153.Ballard JB, Lewis RC (2000) The control of subterranean termites in residential structures using FirstLine ${ }^{\mathrm{TM}}$ termite bait, In: Suiter DR (Eds.), Proceedings of the National Conference on Urban Entomology, Ft. Lauderdale, FL, p. 20.

154. Guillaume M (2001) Les termites Paris troue', Paris perce', Paris menace'? Insectes 120: 16-18.

155. Bagne`res AG (2003) Les Termites dans le Centre. Microscoop/ Hors $\mathrm{se}^{\prime}$ rie, Numéro 12 Octobre. Le Journal De LaDe' le' gation CentreAuvergne-Limousin du CNRS: 50-51.

156.Wood TG, Sands WA (1978) The role of termites in ecosystems. In Production ecology of ants and termites MV Brian (Eds.), Cambridge University Press, pp.245-292.

157. Marini M, Mantovani B (2002) Molecular relationships among European samples of Reticulitermes (Isoptera, Rhinotermitidae). Mol Phylogenet Evol 22(3): 454-459.

158. Lee KE, Wood TG (1971) Termites and soil. London: academic Press. pp. 251.

159. Collins NM (1989) Termites. In Ecosystems of the World: Tropical Rain Forest Ecosystems, Lieth H, Werger MJA (Eds.) pp. 455-472.

160. Kambhampati S, P Eggleton (2000) Phylogenetics and Taxonomy. In: Termites: Evolution, Sociality, Symbioses, Ecology, T Abe, DE Bignell, M Higashi (Eds.), Kluwer Academic Publishing, Dordrecht p. 1-23.

161. Fougerousse M, Perlade J (1975) The present status of termites in Europe. In: Record of the 1975 Annual Convention of the British Wood Preserving Association. British Wood Preserving Association, Cambridge, UK, pp. 35-49.

162. Feytaud J (1924) Le termite de Saintonge. CR Acad Sci 178: 241-244.

162. Feytaud J (1925) Existe-il plusieurs races de Reticulitermes lucifugus (Rossi)? Rev Zool Agr Appl, XXIV. 8: 161-169.

163. Feytaud J (1966) Le peuple des termites. Que sais-je pp. 213: 128.

164. Lash JH (1952) A new species of Reticulitermes (Isoptera) from Jerusalem. Am Mus Novitates 1575: 1-7.

165. Grasse PP (1954) Origine et repartition geographique des termites francais. Annals de I, Ecole Nationale d, agriculture de Montpellier 29. 17-21.

166. Aber A, Fontes LR (1993) Reticulitermes lucifugus (Isoptera, Rhinotermitidae), a pest of wooden structures, is introduced into the South American continent. Sociobiology 21: 335-339.

167. Cabrera P, Camusseicht A (1997) The presence of Reticulitermes hesperus Banks (Isoptera, Rhinotermitidae) in Chile. XIX National Congress of Entomology, University of La Serena. La Serena, Chile. 
168. Clement JL, Lemaire M, Nagnan P, Escoubas P, Bagnères AG (1988) Chemical ecology of European termites of the genus Reticulitermes. Allomones, pheromones and kairomones. Sociobiology 15: 19-24.

169. Hrdy I (1961) Contribution to the knowledge of European species of the genus Reticulitermes (Holmgren). Acta Faunistica Entomologica Musei Nationalis Pragae 7: 97-107.

170. Grasse PP, R Chauvin (1946) Leffet de groupe et la survie des neuters dans les societe dinsectes. Revue Scientific 82: 461-464.

171. Gay FJ, T Greaves, FG Holdaway, AH Wetherly (1955) Standard laboratory colonies of termites for evaluating the resistance of timber timber preservatives and other materials to termite attack. Melbourne: CSIRO p. 60.

172. Feytaud J (1946) Le people des termites. Paris, Presses Universitaire de France pp. 127.

173. Jacquiot C (1956) Les termites de France. CTBA Document, 7 pp.

174. Su NY, M Tamashiro, JR Yates, MI Haverty (1984) Foraging behavior of the Formosan subterranean termite (Isoptera: Rhinotermitidae). Environ. Entomol 13: 1466-1470.

175. Su NY, PN Scherer (2003) Feeding site selection by workers of the Formosan subterranean termite Coptotermes formosanus (Isoptera: Rhinotermitidae) Ña reanalysis of field data from a mark-release study. Bull. Entomol Res 93(5): 467-473.

176. Suarez ME, BL Thorne (2000) Rate, amount, and distribution pattern of alimentary fluid transfer via trophallaxis in three species of termites (Isoptera: Rhinotermitidae, Termopsidae). Ann. Entomol. Soc. Am. 93(1): 145-155.

177. Kard, B. 2001. Gulfport studies stay the course. Pest Control 69: 30-33.

178. Tomalski M, Vargo EL (2004) Chain reaction: studies shed light on mechanisms of transfer of a nonrepellent termiticide. Pest Control p. 51-53.

179. Delgrade S, Lefevre R (2002) Evaluation of the Effects of Thiamethoxam on Three Species of African Termite (Isoptera: Termitidae) Crop Pests. J Econ Entomol 95(3): 531-536.

180. Scheffrahn RH, Su NY, Busey P (1997) Laboratory and field evaluations of selected chemical treatments for control of drywood termites (Isoptera: Kalotermitidae). J Econ Entomol 90(2): 492-502.

181. Karl AH, Rust MK (2005) Effect of hexaflumuron on mortality of the Western subterranean termite (Isoptera: Rhinotermitidae) during and following exposure and movement of hexaflumuron in termite groups. Pest Manag Sci 61(6): 517-531.

182. Lewis VR, MI Haverty, DS Carver, C Fouche (1996) Field comparison of sand or insecticide barriers for control of Reticulitermes spp. (Isoptera: Rhinotermitidae) infestations in northern California. Sociobiology 28 327-335.

183. Su NY, RH Scheffrahn (1993) Laboratory evaluation of two chitin synthesis inhibitors, hexaflumuron and diflubenzuron, as bait toxicants against Formosan and eastern subterranean termites (Isoptera: Rhintotermitidae). J Econ Entomol 86: 1453-1457.

184. Imamura Y, Fujii Y (1995) Analysis of feeding activities of termites by AE monitoring of infested wood. Mokuzaihozon 21(2): 11-19.

185. Fujii Y, Imamura Y, Iwatsubo E, Yamamoto S (1997) Control of Termite Attack Using a Trapping Method and Acoustic Emission (AE) Monitoring. A case study at an electric power plant. MOKUZAI HOZON (Wood Protection) 23(3): 111-120.

186. Chen J, Henderson G (1996) Determination of feeding preferences of Formosan subterranean termite (Coptotermes formosanus Shiraki) for some amino acid additives. Journal of Chemical Ecology 22(12): 23592369.

187. Rust MK, Haagsma KA, Nyugen J (1996) Enhancing foraging in western subterranean termites. Sociobiology 28(3): 275-286.
188. Robinson WH (1996) Integrated pest management in the urban environment. American Entomologist 42(2): 76-78.

189.Reinhard J, Hertel H, Kaib M (1997) Systematic search for food in the subterranean termite Reticulitermes santonensis De Feytaud (Isoptera, Rhinotermitidae). Insectes Sociaux 44(2): 147-158.

190.Acda MN (2007) Toxicity of thiamethoxam against Philippine subterranean termites. 6pp. Journal of Insect Science 7: 26.

191.Byron L Reid, Robert Brinkmann, Graeme Smith, Kiyoto Ishizaka, Boy Palis, et al. (2002) Imidacloprid use in termite control operations globally and changing use patterns in the United States. Proceedings of the 4th International conference on urban Pests pp. 355-368.

192. Chen J, Henderson G, Grimm CC, Lloyd SW, Laine RA (1998) Naphthalene in Formosan subterranean termite carton nests. J Agric Food Chem 46: 2337-2339.

193.Crawley MJ (2002) Statistical computing: An introduction to data analysis using S-Plus. Chichester, Jhon wiley \& Sons pp. 761.

194.Cleveland LR (1926) Symbiosis among animals with special reference to termites and their intestinal flagellates. Q Rev Biol 1(1): 51-64.

195.Forschler BT (1996a) Incidence of feeding by the eastern subterranean termite (Isoptera: Rhinotermitidae) in laboratory bioassay. Sociobiology 28: 265-273.

196.Forschler BT (1996b) Baiting Reticulitermes (Isoptera: Rhinotermitidae) field colonies with abamectin and zinc borate treated cellulose in Georgia. Sociobiology 28: 459-484.

197. Gahlhoff J, Koehler PG (1999) To kill or not to kill? Pest Control Technol. 27(3): 22-28.

198. Grasse PP (1939) Comportment et particularite,s physiologiques des soldates de termites. Bull Soc zool Fr 64: 251-262.

199. Grasse PP (1954) Origine et re partition geographique des termites franc, ais. Annales de lOEcole Nationale doHorticulture de Montpellier 24: $1-10$.

200.Haverty, MI, KA Copren, GM Getty, VR Lewis (1999) Agonistic behavior and cuticular hydrocarbon phenotypes of colonies of Reticulitermes (Isoptera: Rhinotermitidae) from northern California. Ann Entomol Soc Am 92: 269-277.

201. Howard RW, MI Haverty (1979) Comparison of feeding substrates forevaluating effects of insect growth regulators on subterranean termites. J Ga Entomol Soc 14: 3-7.

202Krishna K (1969) Introduction, In K. Krishna and FM Weeneer (Eds.), Biology of termites, vol. 1 Academic Press, New York, USA, pp. 1-17.

203.Kuriachan I, Gold RE (1998) Evaluation of the ability of Reticulitermes flavipes, a subterranean termite, to differentiate between termiticide treated and untreated soil in laboratory tests. Sociobiology 32(1): 151168.

204.Laura N Remmen, Nan Y Su (2005) Tunneling and mortality of eastern and formosan subterranean termites (Isoptera: Rhinotermitidae) in sand treated with thiamethoxam or fipronil. J Econ Entomol 98(3): 906-910.

205. Lenz M, Gleeson, PV, Miller LR, Abbey HM (1996) How Predictive are Laboratory Experiments for Assessing the Effects of Chitin Synthesis Inhibitor (CSI) on Field Colonies of Termites? A Comparison of Laboratory and Field Data from Australian Mound-building Species of Termite. Stockholm: International Research Group on Wood Preservation.

206. Lewis VR, MI Haverty, GM Getty, KA Copren, C Fouche (1998) Monitoring station for studying populations of Reticulitermes (Isoptera: Rhinotermitidae) in California. Pan Pac Entomol 74(3): 121-133.

207. Mo J, Pan C, Zhang S, Chen C, Hei H, et al. (2005) Toxicityof acetamiprid to workers of Reticulitermes flaviceps (Isoptera: Rhinotermitidae), Coptotermes formosanus (Isoptera: Rhinotermitidae)and Odontotermes formosanus (Isoptera: Termitidae) J Pestic Sci 30(3): 187-191. 
208. Pawson BM, RE Gold (1996) Evaluation of baits for termites (Isoptera: Rhinotermitidae) in Texas. Sociobiol. 28: 485-510.

209. Perez Farinos G, G Smagghe, V Marco, L Tirry, P Castañera (1998) Effects of topical application of hexaflumuron on adult sugar beet weevil, Aubeonymus mariaefranciscae on Embryonic development: Pharmacokinetics in adults and embryos. Pestic. Biochem Phys 61(3): 169-182.

210. Potter MF, EA Eliason, K Davis, RT Bessin (2001) Managing subterranean termites (Isoptera: Rhinotermitidae) in the Midwest with a hexaflumuron bait and placement considerations around structures. Sociobiology 38(3): 565-568.

211.Reid B (2001) Liquidate termite colonies with non-repellent technology. Pest Control 69(2): 54-56.

212.Shimiz S, M Yamaji (2003) Effect of density of the termite, Reticulitermes speratus Kolbe (Isoptera: Rhinotermitidae), on the susceptibilities to Metarhizium anisopliae. Appl. Entomol. Zool 38(1): 125-130.

213.Su NY (2003) Baits as a tool for population control of the formosan subterranean termite. Sociobiology 41(1): 177-192.

214.Su NY (2005) Directional change in tunneling of subterranean termites (Isoptera: Rhinotermitidae) in response to decayed wood attractants. J Econ Entomol 98(2): 471-475.

\section{ISSN: 2574-1241}

DOI: 10.26717/BJSTR.2018.11.002107

Khalid Z Rasib. Biomed J Sci \& Tech Res

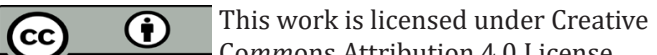

This work is licensed under Creative
Commons Attribution 4.0 License

Submission Link: https://biomedres.us/submit-manuscript.php
215.Su NY, RH Scheffrahn (1990) Potential of insect growth regulators as termiticides: A review. Sociobiology 17(2): 313-328.

216.Su NY, Scheffrahn RH (1996) Fate of subterranean termite colonies (isoptera) after bait applications \pm an update and review. Sociobiology 27: 253-75.

217.Su NY, PM Ban, RH Scheffrahn (1993) Foraging populations and territories of the eastern subterranean termite (Isoptera: Rhinotermitidae) in southeastern Florida. Environ Entomol 22(5): 11131117.

218.Su NY, RH Scheffrahn, PM Ban (1995) Effects of Sulfluramid-treated bait blocks on field colonies of the Formosan Subterranean Termite (Isoptera: Rhinotermitidae). J Econ Entomol 88(5): 1343-1348.

219. Su NY, Ban PM, RH Scheffrahn (1997) Remedial baiting with hexaflumuron in above-ground stations to control structure-infesting populations of the formosan subterranean termite (Isoptera: Rhinotermitidae). J Econ Entomol 90(3): 809-817.

220.Thorne BL, Traniello JFA (2003) Comparative social biology of basal taxa of ants and termites. Annu. Rev Entomol 48: 283-306.

221. United Nation Environment Programme UNEP (Chemicals) (2002) Finding alternatives organic pollutants (POPs) for termite management. UNEP/FAO/Global IPM Facility Expert Group on Termite Biology and Management. Stockholm Convention.

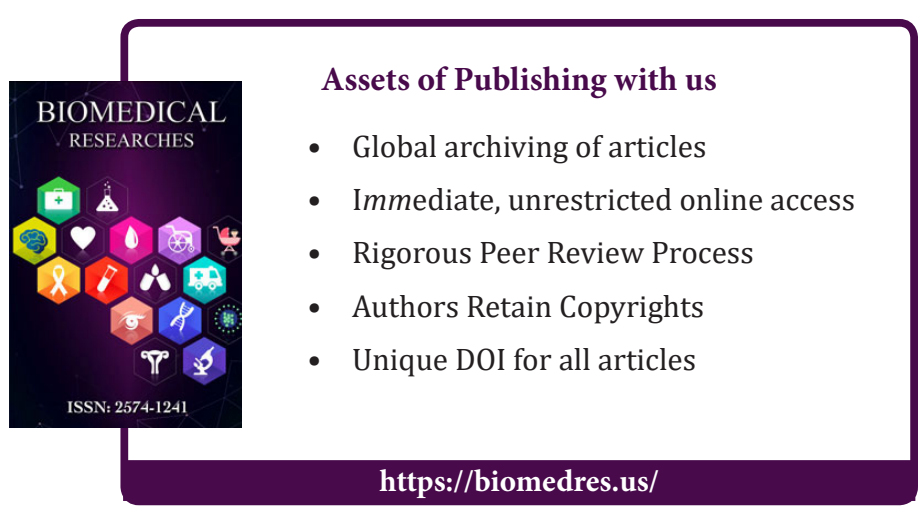

